\title{
Bidirectional Influence of Limbic GIRK Channel Activation on Innate Avoidance Behavior
}

\author{
Baovi N. Vo, ${ }^{1}{ }^{\circledR}$ Ezequiel Marron Fernandez de Velasco, ${ }^{2}$ Timothy R. Rose, ${ }^{1}$ Hannah Oberle,${ }^{2}$ Haichang Luo, ${ }^{1}$ \\ Corey R. Hopkins, ${ }^{3}$ and ${ }^{\circledR}$ Kevin Wickman ${ }^{2}$ \\ ${ }^{1}$ Graduate Program in Pharmacology, University of Minnesota, Minneapolis, Minnesota 55455, ${ }^{2}$ Department of Pharmacology, University of \\ Minnesota, Minneapolis, Minnesota 55455, and ${ }^{3}$ Department of Pharmaceutical Sciences, College of Pharmacy, University of Nebraska Medical \\ Center, Omaha, Nebraska 68198
}

Systemic administration of ML297, a selective activator of G-protein-gated inwardly rectifying $\mathrm{K}^{+}$(GIRK) channels, decreases innate avoidance behavior in male C57BL/6J mice. The cellular mechanisms mediating the ML297-induced suppression of avoidance behavior are unknown. Here, we show that systemic ML297 administration suppresses elevated plus maze (EPM)induced neuronal activation in the ventral hippocampus (vHPC) and basolateral amygdala (BLA) and that ML297 activates GIRK1-containing GIRK channels in these limbic structures. While intracranial infusion of ML297 into the vHPC suppressed avoidance behavior in the EPM test, mirroring the effect of systemic ML297, intra-BLA administration of ML297 provoked the opposite effect. Using neuron-specific viral genetic and chemogenetic approaches, we found that the combined inhibition of excitatory neurons in CA3 and dentate gyrus (DG) subregions of the vHPC was sufficient to decrease innate avoidance behavior in the EPM, open-field, and light-dark tests in male C57BL/6J mice, while performance in the marble-burying test was not impacted. Furthermore, genetic ablation of GIRK channels in CA3/DG excitatory neurons precluded the suppression of avoidance behavior evoked by systemic ML297 in the EPM test. Thus, acute inhibition of excitatory neurons in the ventral CA3 and DG subregions of the vHPC is necessary for the apparent anxiolytic efficacy of systemic ML297 and is sufficient to decrease innate avoidance behavior in male $\mathrm{C} 57 \mathrm{BL} / 6 \mathrm{~J}$ mice.

Key words: anxiety; basolateral amygdala; elevated plus maze; Kir3; ML297; ventral hippocampus

Significance Statement

We interrogated the cellular mechanisms underlying the apparent anxiolytic efficacy of ML297, a selective activator of G-protein-gated inwardly rectifying $\mathrm{K}^{+}$(GIRK) channels and promising lead compound. Intracranial infusion of ML297 into the ventral hippocampus (vHPC) and basolateral amygdala (BLA) complex exerted opposing influence on innate avoidance behavior in male C57BL/6J mice, the former recapitulating the suppression of avoidance behavior evoked by systemic ML297. Using viral genetic and chemogenetic approaches, we showed that combined inhibition of excitatory neurons in CA3 and dentate gyrus (DG) subregions of the vHPC is sufficient to decrease innate avoidance behavior in male mice and mediates the decrease in avoidance behavior evoked by systemic ML297. These findings establish a foundation for future investigations into the therapeutic potential of GIRK channel modulation in anxiety disorders.

Received Nov. 2, 2020; revised May 14, 2021; accepted May 19, 2021.

Author contributions: B.N.V. and K.W. designed research; B.N.V., E.M.F.d.V., H.O., H.L., and T.R.R. performed research; C.R.H. contributed unpublished reagents/analytic tools; B.N.V., E.M.F.d.V., H.O., H.L., and K.W. analyzed data; B.N.V., E.M.F.d.V., H.O., H.L., T.R.R., C.R.H., and K.W. wrote the paper.

Acknowledgements: We thank Zhilian Xia, Nicholas Carlblom, Mehrsa Zahiremami, and Courtney Wright for taking care of the mouse colony; Janna Moen, Jenna Robinson, and Margot DeBaker for assisting with cFos immunohistochemistry; Dr. Yasushi Nakagawa for providing support for the viral fidelity validation experiments; Dr. Megan Tipps and Dr. Nora McCall for providing valuable feedback on the manuscript; and Dr. C. David Weaver for providing some of the ML297 used for this study. This work was supported by National Institutes of Health Grants DA034696 (to K.W.), AA027544 (to K.W.), MH107399 (to K.W., C.R.H.), and DA007234 (to T.R.R.); a Wallin Neuroscience Discovery Fund Award (K.W.); and a Doctoral Dissertation Fellowship from the University of Minnesota (B.N.V.).

The authors declare no competing financial interests.

Correspondence should be addressed to Kevin Wickman at wickm002@umn.edu.

https://doi.org/10.1523/JNEUROSCI.2787-20.2021

Copyright $\odot 2021$ the authors

\section{Introduction}

Anxiety is a state of apprehension and enhanced vigilance, triggered by anticipation of a future threat or internally generated, that often results in avoidance behavior (Hendriks et al., 2016; Arnaudova et al., 2017; Hofmann and Hay, 2018). Approachavoidance conflict models, including elevated plus maze (EPM), open-field test, and light-dark test, are common assays for studies of innate avoidance or anxiety-related behavior in rodents (Calhoon and Tye, 2015). Drugs with anxiolytic efficacy in humans reduce avoidance behavior in rodents (Bourin, 2015; Calhoon and Tye, 2015), and individuals suffering from anxiety disorders show avoidance to potentially hazardous stimuli (Calhoon and Tye, 2015). A recent attempt to adapt the EPM 
model for human subjects demonstrated that anxiety level correlates positively with open arm avoidance, and that benzodiazepine treatment suppresses this behavior (Biedermann et al., 2017).

The predictive and face validity of approach-avoidance conflict models, and their straightforward implementation in rodents, has made them popular tests for probing the anatomic, cellular, and molecular mechanisms underlying innate avoidance behavior. Several lines of evidence have implicated the ventral hippocampus (vHPC) and basolateral amygdala (BLA) complex in innate avoidance behavior (Fanselow and Dong, 2010; Oler et al., 2010; Wang et al., 2011; Felix-Ortiz et al., 2013; Bannerman et al., 2014; Stujenske et al., 2014; Calhoon and Tye, 2015; Janak and Tye, 2015; Yang and Wang, 2017; Jimenez et al., 2018; Sorregotti et al., 2018; Padilla-Coreano et al., 2019). For example, lesions of the vHPC are anxiolytic (Kjelstrup et al., 2002; Bannerman et al., 2003). Neuronal activity in the vHPC and BLA complex also correlates with position of animals (i.e., open or closed arms) on the EPM (Adhikari et al., 2010, 2011; Wang et al., 2011; Jimenez et al., 2018). Less is known regarding the neuronal populations and molecular mechanisms within these limbic structures that regulate innate avoidance behavior.

Several drugs prescribed for anxiety disorders, including selective serotonin reuptake inhibitors and buspirone, work by enhancing inhibitory G-protein signaling in neurons (Bystritsky et al., 2013; Strawn et al., 2018). G-protein-gated inwardly rectifying $\mathrm{K}^{+}$(GIRK/Kir3) channels mediate the direct/postsynaptic G-protein-dependent effects of inhibitory neurotransmitters throughout the CNS (Slesinger and Wickman, 2015). GIRK channels are activated in a G $\beta \gamma$-dependent manner, following stimulation of G-protein-coupled receptors linked to inhibitory $\left(\mathrm{G}_{\mathrm{i} / \mathrm{o}}\right)$ G-proteins (Lüscher and Slesinger, 2010; Luján et al., 2014). Most neuronal GIRK channels contain GIRK1 and GIRK2 (Luján and Aguado, 2015). Indeed, GIRK1 and GIRK2 exhibit broad and overlapping distributions in the rodent brain, including the hippocampus and amygdala (Karschin et al., 1996; Lüscher et al., 1997; Koyrakh et al., 2005). Moreover, genetic ablation of Girk1 or Girk2 in mice yields a complete loss or substantial reduction in GIRK channel activity in most neuron populations (Luján et al., 2014).

Constitutive ablation of the Girk1/Kcnj3 or Girk2/Kcnj6 gene in male mice reduces innate avoidance behavior in the EPM (Pravetoni and Wickman, 2008). Interestingly, systemic administration of ML297, a potent direct activator of GIRK1-containing GIRK channels (Kaufmann et al., 2013), also reduces innate avoidance behavior in EPM, in a GIRK-dependent manner (Wydeven et al., 2014; Vo et al., 2019). ML297 did not alter motor activity, impact performance in the forced swim test, or evoke a conditioned place preference (Wydeven et al., 2014).

Given the broad distribution of GIRK channels in the brain, the site(s) of action of ML297 that underpin its influence on innate avoidance behavior are unclear. Here, we show that systemic ML297 blunts neuronal activation in the vHPC and BLA complex induced by EPM exposure. Intra-vHPC infusion of ML297 decreases innate avoidance behavior in male $\mathrm{C} 57 \mathrm{BL} / 6 \mathrm{~J}$ mice, recapitulating the impact of systemic ML297, whereas ML297 infusion into the BLA complex exerts the opposite effect. In addition, combined inhibition of excitatory neurons in the CA3 and dentate gyrus (DG) subregions of the vHPC is necessary for the anxiolytic efficacy of systemic ML297, and sufficient to decrease innate avoidance behavior in male mice.

\section{Materials and Methods}

\section{Animals}

All animal experiments were approved by the Institutional Animal Care and Use Committee at the University of Minnesota. The generation of Girk1 ${ }^{-1-}$ (RRID:MGI:3041949) and Girk1 $1^{\text {fl/fl }}$ mice was described previously (Bettahi et al., 2002; Marron Fernandez de Velasco et al., 2017). TrpC4Cre (Okuyama et al., 2016) and DOCK10Cre (Kohara et al., 2014) mice were provided by Susumu Tonegawa, and GAD67GFP(+) mice (Tamamaki et al., 2003) were provided by Takeshi Kaneko. CaMKIICre (B6.Cg-Tg(Camk2a-cre) T29-1Stl/J; RRID:IMSR_JAX:005359) and Grik4Cre (C57BL/6-Tg (Grik4-cre)G32-4Stl/J; RRID:IMSR_JAX: 006474) mice were obtained from The Jackson Laboratory. All lines were maintained by backcrossing with C57BL/6J mice, also purchased from The Jackson Laboratory. Mice were housed with a 14/10 h light/dark cycle (lights on at 6 A.M. and off at 8 P.M.), and food and water were available ad libitum. All behavioral studies were performed during the light phase.

\section{Reagents}

ML297 $\left(\mathrm{C}_{17} \mathrm{H}_{14} \mathrm{~F}_{2} \mathrm{~N}_{4} \mathrm{O}\right)$ was synthesized in-house or generously provided by C. David Weaver. Clozapine-N-oxide (CNO) was purchased from Tocris Bioscience. Baclofen and CGP54626 were purchased from Sigma-Aldrich. pAAV-hSyn-DIO-hM4Di(mCherry) [RRID:Addgene_ 44362 (Krashes et al., 2011) and pAAV-hSyn-DIO-mCherry (RRID: Addgene_50459) were gifts from Bryan Roth].pAAV-CaMKII $\alpha$-hM4Di (mCherry), pAAV-CaMKII $\alpha$-Cre(mCherry), and pAAV-CaMKII $\alpha$ mCherry plasmids were generated by the University of Minnesota Viral Vector and Cloning Core (VVCC; Minneapolis, MN) using pAAVCaMKII $\alpha$-hChR2(C128S/D156A)-mCherry (RRID:Addgene_35502, a gift from Karl Deisseroth), as the backbone (Yizhar et al., 2011). pAAVmDlx-hM4Di(mCherry) and pAAV-mDlx-mCherry were generated using pAAV-mDlx-GCaMP6f-Fishell-2 (RRID:Addgene_83899, a gift from Gordon Fishell), as the source of the $\mathrm{mDlx}$ promoter/enhancer (Dimidschstein et al., 2016). All vectors were packaged in AAV8 serotype by the VVCC; titers were between 0.7 and $5.5 \times 10^{14}$ genocopies/ $\mathrm{ml}$.

\section{$E P M$}

EPM studies were performed as described (Vo et al., 2019). Briefly, mice were placed in the EPM center facing an open arm and away from the experimenter, and their subsequent activity was recorded for $5 \mathrm{~min}$ by video camera. Time spent in the open arms, closed arms, maze center, total distance traveled, and average velocity were extracted using ANYmaze 5.2 software (Stoelting Co). For intracranial ML297 studies, stylets were removed on test day and replaced with injection cannulae attached to a Pump 11 Elite infusion pump (Harvard Apparatus) and protruding $1 \mathrm{~mm}$ beyond the tip of the guide cannula. After infusions $(250 \mathrm{nl} / \mathrm{min}$, $500 \mathrm{nl} /$ side $)$ of vehicle $(0.1 \%$ DMSO in saline) or ML297 $(1.5,5$, or $15 \mathrm{pmol} / \mathrm{side}$ ), injection cannulae were held in place for 1-2 min. EPM tests were performed immediately thereafter. Following testing, ink was infused through injection cannulae to aid in targeting validation. For chemogenetic and GIRK ablation studies, CNO ( $2 \mathrm{mg} / \mathrm{kg}$ ) or ML297 $(30 \mathrm{mg} / \mathrm{kg})$ was administered on test day via intraperitoneal injection, $30 \mathrm{~min}$ before EPM testing.

\section{c-Fos labeling and quantification}

Animals were euthanized with phenytoin/pentobarbital (150 mg/kg, i.p.) $2 \mathrm{~h}$ after EPM exposure. Following transcardial perfusion and fixation with $4 \%$ paraformaldehyde (PFA), brains were postfixed in 4\% PFA for 4-6 $\mathrm{h}$ and transferred to a $30 \%$ sucrose solution for 2-3 d. Coronal sections $(30 \mu \mathrm{m})$ containing the vHPC and BLA complex were prepared by cryostat and transferred to a $0.1 \mathrm{M}$ PBS solution. Brain sections were rinsed with $\mathrm{PBS}$ and placed in $1 \%$ borohydride for $15 \mathrm{~min}$, and then incubated with rabbit anti c-Fos antibody (catalog \#ABE457, EMD Millipore Corp), diluted 1:1000, overnight at $4^{\circ} \mathrm{C}$. Subsequently, brain sections were rinsed in PBS with 2\% Triton X-100 and placed in goat anti-rabbit secondary antibody (catalog \#550338, BD Biosciences), diluted 1:50, for 1.5-2 h on rotator. After rinses in PBS plus $2 \%$ Triton $\mathrm{X}-100$, brain sections were immersed in Avidin-biotinylated enzyme 
complex HRP (ABC) solution (Vector Labs) for 1.5-2 h, and then rinsed in PBS and placed in a $0.015 \% 3,3^{\prime}$-diaminobenzidine (DAB) solution for $15-30 \mathrm{~min}$. Brain sections were then rinsed again in PBS and mounted on gelatin-coated slides. c-Fos expression was quantified using ImageJ particle analysis. The threshold was automatically set using the Renyi Entropy algorithm (Law et al., 2017). The total cell count of c-Fos $(+)$ cells within the boundaries of the targeted brain regions (i.e., CA1, CA3, DG, and BA) was divided by the targeted areas to obtain density values. Because of the variability in the data across the cohorts of animals, we normalized the density of each subject by the average density of the vehicle and control handling (Veh/control) group included in each cohort.

\section{Slice electrophysiology}

Coronal vHPC $(350 \mu \mathrm{m})$ and BLA $(280 \mu \mathrm{m})$ slices were prepared as previously described for electrophysiological recordings of neurons in the vCA1 (Victoria et al., 2016), CA3 and DG (Anacker et al., 2018), and BLA complex (Tipps et al., 2018). Glass microelectrodes were filled with a K-gluconate-based pipette solution. All recordings were obtained using an EPC10 HEKA amplifier and Patchmaster $2 \times 73.2$ software (HEKA Elektronik), and all measured and command potentials factored in a junction potential $(-15 \mathrm{mV})$ predicted using JPCalc software (Molecular Devices). For rheobase assessments, cells were held in current-clamp mode and given 1-s current pulses, beginning at $-60 \mathrm{pA}$ and progressing in $20 \mathrm{pA}$ increments until spiking was elicited. Somatodendritic currents induced by baclofen $(200 \mu \mathrm{M})$, ML297 $(10 \mu \mathrm{M})$, or CNO $(10 \mu \mathrm{M})$ were measured at a holding potential ( $V_{\text {hold }}$ ) of $-60 \mathrm{mV}$. Holding current, input resistance, and series resistance values were measured throughout each experiment by tracking responses to periodic $(0.2 \mathrm{~Hz})$ voltage steps $(-5 \mathrm{mV}, 800 \mathrm{~ms})$. Only experiments with stable ( $<30 \%$ variation) and low series resistances $(<30 \mathrm{M} \Omega)$ were analyzed.

\section{Intracranial surgery}

Intracranial ML297 experiments were performed as previously described (Kotecki et al., 2015). Briefly, bilateral stainless-steel guide cannulae (26gauge, Plastics One) targeting the vHPC (from bregma: $-3.15 \mathrm{~mm} \mathrm{AP}$, $\pm 3.80 \mathrm{~mm} \mathrm{ML},-3.25 \mathrm{~mm} \mathrm{DV})$ or BLA complex $(-1.50 \mathrm{~mm} \mathrm{AP}, \pm 3.30$ $\mathrm{mm} \mathrm{ML},-4.70 \mathrm{~mm} \mathrm{DV}$ ) were positioned $1 \mathrm{~mm}$ above the infusion target of adult male C57BL/6J mice (eight weeks). Mice were allowed to recover for 7-9 d before EPM testing. For intracranial viral manipulations, microinjectors were created by affixing a 33-gauge stainless steel hypodermic tube within a shorter 26-gauge stainless steel hypodermic tube, and they were attached to polyethylene-20 tubing affixed to $10-\mu l$ Hamilton syringe. Microinjectors were lowered bilaterally to the vCA1 $(-3.15 \mathrm{~mm} \mathrm{AP}, \pm 3.90 \mathrm{~mm} \mathrm{ML},-3.25 \mathrm{~mm} \mathrm{DV})$, vCA3/DG $(-3.15 \mathrm{~mm}$ $\mathrm{AP}, \pm 3.00 \mathrm{~mm} \mathrm{ML},-2.70 \mathrm{~mm} \mathrm{DV}$ ), or BLA complex (from bregma: $-1.50 \mathrm{~mm} \mathrm{AP}, \pm 3.30 \mathrm{~mm} \mathrm{ML},-4.70 \mathrm{~mm} \mathrm{DV}$ ). Viral vectors (vCA1: $400 \mathrm{nl}$, vCA3/DG: $300 \mathrm{nl}, \mathrm{BLA}: 400 \mathrm{nl}$ ) were infused at a rate of $100 \mathrm{nl} /$ min using a Pump 11 Elite infusion pump (Harvard Apparatus). The syringe was left in place for $10 \mathrm{~min}$ following infusion. Electrophysiological validation or behavioral studies were performed four weeks after surgery.

\section{Open-field test}

The open-field test was performed in chambers $(43.38 \times 43.38 \times$ $30.28 \mathrm{~cm}$ ) housed within sound-attenuating cubicles (Med Associates) with overhead illumination (single $2.8-\mathrm{W}$ light bulb), as described (Pravetoni and Wickman, 2008). On test day, mice were placed into a corner of the open field and activity patterns were tracked for $30 \mathrm{~min}$ by infrared sensors. Time spent in the center of the arena $(28.14 \times$ $28.14 \mathrm{~cm}$ ) was analyzed for each subject. For systemic ML297 and chemogenetic studies, ML297 (30 mg/kg, i.p.) or CNO ( $2 \mathrm{mg} / \mathrm{kg}$, i.p.) was administered $30 \mathrm{~min}$ before testing.

\section{Light-dark test}

The light-dark test was performed $3 \mathrm{~d}$ following the open-field test in modified two-compartment chambers (Med Associates; $16.76 \times 12.7 \times$ $12.7 \mathrm{~cm}$ per compartment) housed within sound-attenuating cubicles. One compartment contained white walls and floors, and overhead illumination (single 2.8-W light bulb), while the other compartment contained black walls and floors, without overhead illumination. On test day, mice were acclimated to the testing room for $60 \mathrm{~min}$ before being placed in the black compartment facing the open door to the white compartment, and time spent on each side was tracked for $5 \mathrm{~min}$ by infrared sensors. Percent time spent in the light compartment was measured for each subject using MED-PC IV 4.2 software (Med Associates). For systemic ML297 and chemogenetic studies, ML297 (30 mg/kg, i.p.) or CNO ( $2 \mathrm{mg} / \mathrm{kg}$, i.p.) was administered $30 \mathrm{~min}$ before testing.

\section{Marble-burying test}

The marble-burying test was performed $3 \mathrm{~d}$ following the light-dark test in standard polycarbonate mouse cages $(18 \times 28 \times 13 \mathrm{~cm})$ containing $4-5 \mathrm{~cm}$ of aspen wood chip bedding and 20 dark blue marbles $(1.15-\mathrm{cm}$ diameter) arranged in a $4 \times 5$ array. Mice were acclimated to the testing room for $60 \mathrm{~min}$ before being single-housed for $5 \mathrm{~min}$ in cages containing aspen bedding. Following habituation to the novel substrate, mice were injected with ML297 (30 mg/kg, i.p.) or CNO $(2 \mathrm{mg} / \mathrm{kg}$, i.p.) and placed back into their home cages. After $30 \mathrm{~min}$, mice were placed into a corner of the test cages containing aspen bedding and marbles. Cages were covered with a filter-top lid and mice were free to bury for $30 \mathrm{~min}$. After $30 \mathrm{~min}$, mice were removed and the number of marbles at least two-thirds buried were counted. The percentage of marbles buried was calculated for each subject.

\section{Validation of intracranial targeting}

For intracranial ML297 studies, $250-\mu \mathrm{m}$ coronal sections containing the vHPC and BLA complex were obtained by vibratome, and ink and guide cannulae locations were assessed. Data from mice with mistargeted cannulae placement were excluded from analysis. For viral fidelity validation studies involving GAD67GFP $(+)$ mice, brains were fixed with $4 \%$ PFA via transcardial perfusion, as described above, and $50-\mu \mathrm{m}$ sections containing the vHPC or BLA complex were collected using a sliding microtome. Images $(2 \times$ and $20 \times)$ of fluorescent expression were acquired on an IX81ZDC2 Olympus microscope with disk-scanning unit using MetaMorph Advanced Acquisition v. 7.7.7.0 software (Olympus America Inc.). Dual fluorescent images were overlaid in ImageJ and evaluated using the Allen Mouse Brain Atlas (Lein et al., 2007). Quantification of cells was performed manually in ImageJ using the multipoint selection function. To assess the anatomic scope of viral targeting, $250-\mu \mathrm{m}$ coronal slices of the vHPC and BLA complex were obtained, and $2 \times$ images of bright-field and fluorescent viral expression were acquired. Only data from mice in which the majority $(>70 \%)$ of viral-driven fluorescence was confined to the targeted brain regions were included.

\section{Experimental design and statistical analyses}

Male mice were used in this study because the impact of genetic ablation of Girk1 and Girk2 (Pravetoni and Wickman, 2008), as well as systemic ML297 (Wydeven et al., 2014), on innate avoidance behavior was shown in male mice. In addition, sex differences in EPM performance in C57BL/6 mice have been reported (An et al., 2011), and because the estrous cycle influences the performance of female rodents in the EPM test at baseline and in response to drug treatment (Marcondes et al., 2001; D'Souza and Sadananda, 2017; Yohn et al., 2020). All behavioral experiments were performed in a blind fashion; experimenters did not know the drug or viral treatment status of subjects during testing. Group size determinations were based on effect sizes observed in related experiments, or estimated from pilot studies and previous publications (Wydeven et al., 2014; Vo et al., 2019). Data are presented throughout as the mean \pm SEM. Statistical analyses were performed using Prism 8 (GraphPad Software). Data were analyzed with two-tailed $t$ test, Welch's $t$ test, Mann-Whitney test, one-way ANOVA, or two-way ANOVA, as appropriate. Pairwise comparisons were performed with Tukey's or Bonferroni multiple post hoc tests when $F$ was significant and there was no variance in homogeneity. Data points that fell $>2$ SDs outside of the group mean were excluded from analysis. Differences were considered significant if $p<0.05$. 
A

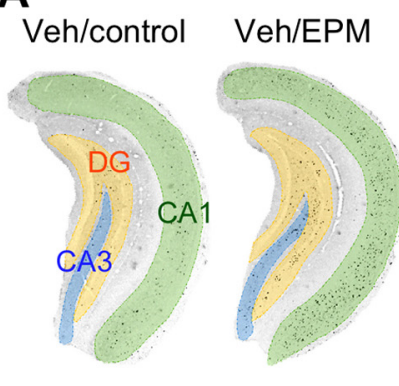

E

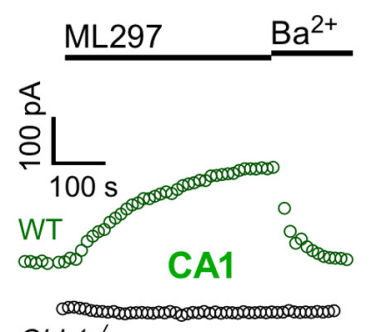
Girk1 $^{-1-}$
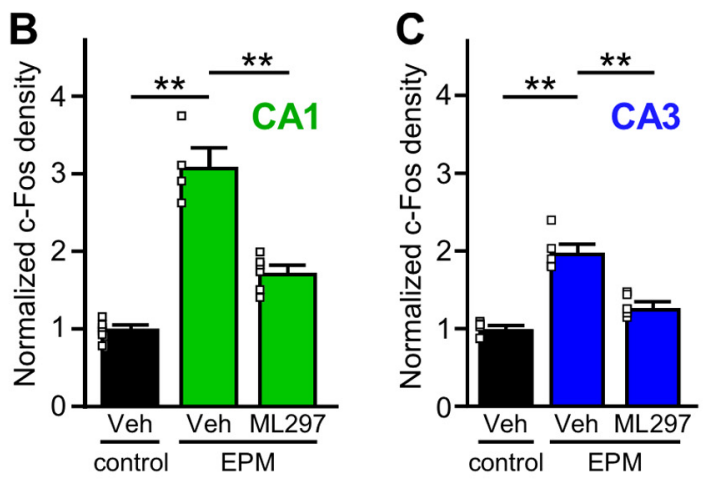

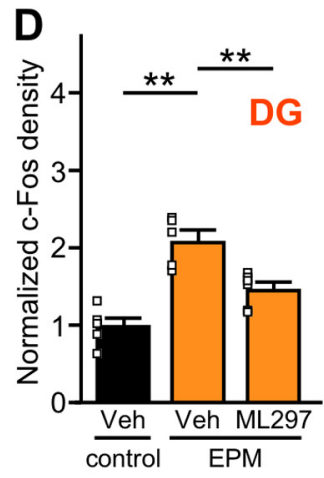

G

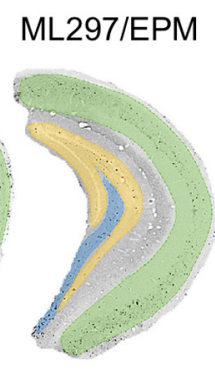

F
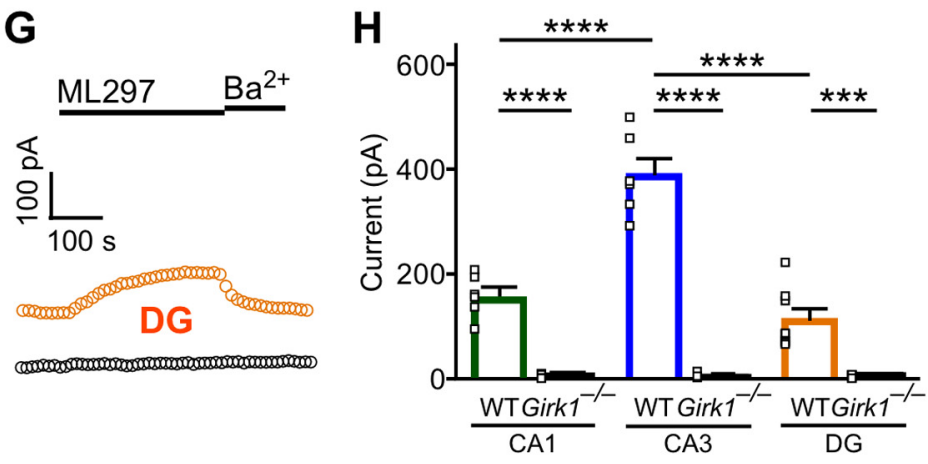

I

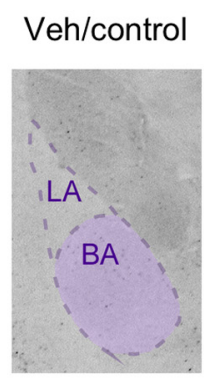

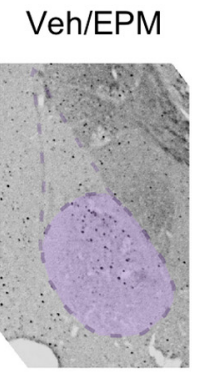
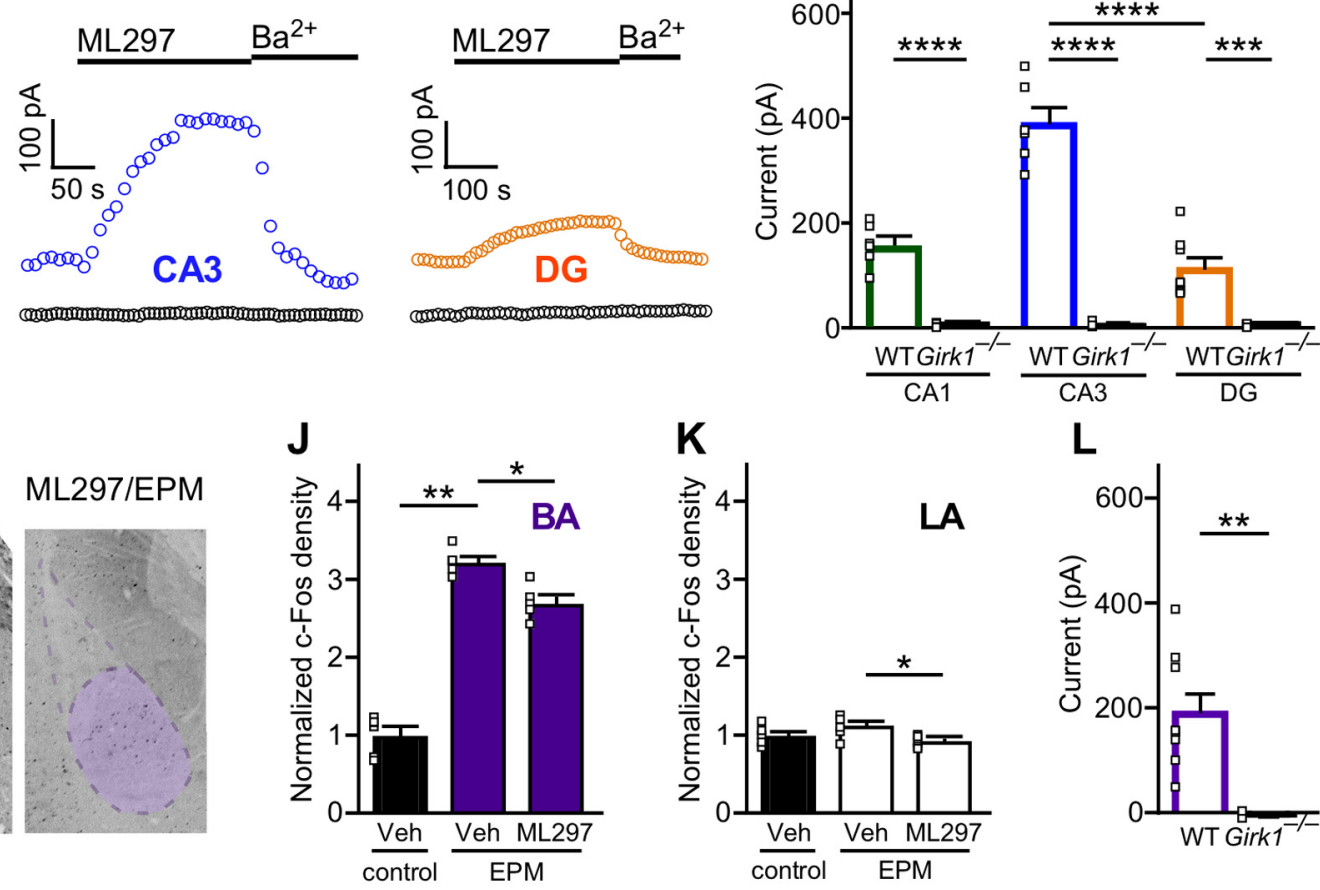

Figure 1. Impact of ML297 on EPM-induced c-Fos expression in the vHPC and BLA. $A$, Representative images of c-Fos expression in the CA1, CA3, and DG subregions of the vHPC in mice receiving vehicle and control handling (Veh/control), vehicle and EPM exposure (Veh/EPM), and ML297 (30 mg/kg, i.p.) and EPM exposure (ML297/EPM). B-D, Comparison of c-Fos density in vCA1, vCA3, and vDG subregions of subjects in Veh/control, Veh/EPM, and ML297/EPM groups. Statistical comparisons were made using the Mann-Whitney test $\left({ }^{* *} p<0.01\right)$, with density values obtained from normalization by the mean of the Veh/control group in each vHPC subregion ( $N=4-6$ mice/group). $E$ G, Representative currents induced by ML297 (10 $\mu \mathrm{m})$ in vCA1 and vCA3 pyramidal neurons, and vDG granule cells, in slices from male C57BL/6J (wild type; WT) and Girk $1^{-/-}$ mice. Currents were reversed by bath application of $0.3 \mathrm{~mm} \mathrm{Ba}{ }^{2+}$, which blocks GIRK channels. $\boldsymbol{H}$, Summary of ML297-induced somatodendritic currents in CA1 pyramidal neurons ( $N=2-3$ mice $n=6$ experiments per group), CA3 pyramidal neurons $(N=1-2, n=3-6)$, and DG granule cells $(N=2-3, n=8)$ in slices from WT and Girk $1^{-/-}$ mice. Main effects of genotype $\left(F_{(1,31)}=194.7, p<0.0001\right)$ and vHPC subregion $\left(F_{(2,31)}=27.19, p<0.0001\right)$ were detected, along with an interaction between genotype and subregion $\left(F_{(2,31)}=26.35, p<0.0001\right)$; ${ }^{* *} p<0.001$ and ${ }^{* * * *} p<0.0001$, respectively. $I$, Representative images of $c-F 0$ s expression in the BA and LA subregions of the BLA in vehicle/no EPM, vehicle/EPM, ML297/EPM groups. $\boldsymbol{J}, \boldsymbol{K}$, Comparison of c-Fos density in LA and BA and subregions of subjects in Veh/control, Veh/EPM, and ML297/EPM groups. Statistical comparisons were made using the Mann-Whitney test $\left({ }^{*} p<0.05\right.$ and ${ }^{* *} p<0.01$, respectively), with density values obtained from normalization by the mean of the Veh/control group in each BLA subregion ( $N=5-6$ mice/group). $L$, Summary of ML297-induced somatodendritic currents measured in BA principal neurons ( $N=1-2$ mice, $n=3-9$ total recordings/group) in slices from WT and Girk $1^{-/-}$mice $\left(U=0,{ }^{* *} p=0.0091\right.$; Mann-Whitney test).

\section{Results}

ML297-induced suppression of EPM-induced neuronal activation in the vHPC and BLA complex

We began by evaluating the impact of EPM exposure on neuronal activation in the vHPC and BLA complex of male C57BL/6J mice, as assessed by immunolabeling for the immediate early gene c-Fos (Gallo et al., 2018). Consistent with prior reports (Silveira et al., 1993; Linden et al., 2004), EPM exposure increased c-Fos expression in the vHPC, with significant increases seen in CA1, CA3, and DG subregions of the vHPC $\left({ }^{* *} p<0.01\right.$; Mann-Whitney test; Fig.
$1 A-D)$. EPM exposure also increased c-Fos expression in the basal (BA) subregion of the BLA complex $\left({ }^{* *} p<0.01\right.$; Mann-Whitney test; Fig. $1 I, J)$, which shares reciprocal connections with the vHPC and other brain regions implicated in anxiety and avoidance behavior (Calhoon and Tye, 2015; Janak and Tye, 2015). c-Fos labeling in the lateral (LA) subregion of the BLA complex was not significantly impacted by EPM exposure ( $p=0.2468$; Mann-Whitney test; Fig. $1 K$ ). Systemic ML297 administration before EPM exposure blunted the EPM-evoked increase in c-Fos labeling in all vHPC subregions $\left({ }^{* *} p<0.01\right.$; Mann-Whitney test). A 
small but significant ML297-induced suppression of c-Fos labeling was also observed in the BLA subregions $\left({ }^{*} p<0.05\right.$; Mann-Whitney test).

\section{ML297-induced activation of GIRK channels in the vHPC and BLA}

GIRK channels containing GIRK1 and GIRK2 mediate the postsynaptic G-protein-dependent inhibitory effect of GABA and other inhibitory neurotransmitters in CA1 pyramidal neurons (Koyrakh et al., 2005), and these subunits have been implicated in GIRK channel formation in other HPC neuron populations, including CA3 pyramidal neurons and DG granule cells (Karschin et al., 1996; Lüscher et al., 1997). To determine whether ML297 selectively evokes GIRK-dependent currents in vHPC CA1 and CA3 pyramidal neurons, and DG granule cells, we next evaluated ML297-induced somatodendritic currents in slices from adult male C57BL/6J and Girk1 ${ }^{-/-}$mice. ML297-induced somatodendritic currents were observed in all targeted neuron populations from C57BL/6J mice, but not in slices from Girk1 $1^{-/}$mice (Fig. $1 E-G$ ). ML297-induced currents in vCA3 pyramidal neurons from C57BL/ $6 \mathrm{~J}$ mice were notably larger than currents measured in vCA1 pyramidal and vDG neurons [significant effects of genotype $\left(F_{(1,31)}=\right.$ 194.7, $\left.{ }^{* * * *} p<0.0001\right)$ and vHPC subregion $\left(F_{(2,31)}=27.19\right.$, $\left.{ }_{* * * *} p<0.0001\right)$ and interaction between genotype and subregion $\left(F_{(2,31)}=26.35,{ }^{* * *} p<0.0001\right)$; Fig. $\left.1 H\right]$.

Although GIRK channel subunit expression has been documented in the BLA complex (Karschin et al., 1996), functional evidence supporting the existence of GIRK1-containing GIRK channels is limited (Tipps et al., 2018). As such, we also probed for ML297-induced, GIRK-dependent responses in BA principal neurons, identified based on established morphologic and electrophysical properties (Tipps et al., 2018). ML297 evoked GIRK-dependent somatodendritic currents in all BA principal neurons from C57BL/6J mice, but not Girk ${ }^{-/-}$mice $\left(U=0,{ }^{* *} p=0.0091\right.$; MannWhitney test; Fig. 1L). Thus, ML297 activates GIRK1-containing GIRK channels in excitatory neurons in the vHPC and BA.

\section{Bi-directional influence of intracranial ML297 on innate avoidance behavior}

To examine the behavioral impact of GIRK channel activation in the vHPC and BA on EPM performance, we administered ML297 via intracranial infusion to the vHPC (Fig. $2 A, C$ ) or BA (Fig. 2G,I) of adult male C57BL/6J mice. Intra-vHPC ML297 dose dependently increased time spent in the open arms of the $\operatorname{EPM}\left(F_{(3,36)}=7.36, p=0.0006\right.$; one-way ANOVA; Fig. $\left.2 B, D\right)$, at the expense of time spent in the closed arms $\left(F_{(3,36)}=4.52\right.$, $p=0.0086$; one-way ANOVA; Fig. $2 E$ ). In contrast, intra-BA ML297 dose dependently decreased time spent in the open arms of the $\operatorname{EPM}\left(F_{(3,34)}=4.047, p=0.0146\right.$; one-way ANOVA; Fig. $2 H, J)$. Infusion of ML297 into either brain region had no impact on total distance traveled $\left[F_{(3,36)}=1.20, p=0.3251\right.$ (vHPC), $F_{(3,34)}=1.198, p=0.3252(\mathrm{BA})$; one-way ANOVA; Fig. $\left.2 F, L\right]$, or on average velocity $\left[F_{(3,36)}=1.14, p=0.3434(\mathrm{vHPC}), F_{(3,34)}=\right.$ 1.166, $p=0.3371$ (BA); one-way ANOVA]. Thus, intra-vHPC and intra-BA infusion of ML297 yielded divergent outcomes in the EPM test, with intra-vHPC ML297 recapitulating the suppression of avoidance behavior seen with systemic ML297 (Wydeven et al., 2014; Vo et al., 2019).

\section{Impact of chemogenetic inhibition of BA principal and GABA neurons on innate avoidance behavior}

To better understand how ML297-induced neuronal inhibition within the vHPC and BA impacts innate avoidance behavior, we employed neuron-specific, viral chemogenetic approaches targeting excitatory/glutamatergic or inhibitory/GABAergic neuron populations. As AAV/CaMKII $\alpha$-based vectors afford selective access to excitatory/principal neurons in the BLA (Tye et al., 2011), we infused AAV8-CaMKII $\alpha$-hM4Di(mCherry) or AAV8CaMKII $\alpha$-mCherry control vector bilaterally into the BA of male C57BL/6J mice (Fig. 3A,B). In slice electrophysiological validation studies, the hM4Di agonist CNO increased the rheobase (decreased the excitability) of hM4Di-expressing, but not control, BA principal neurons $\left(t_{(7.578)}=6.707,{ }^{* * *} p=0.0002\right.$; unpaired Student's $t$ test with Welch's correction; Fig. 3C). Consistent with our previous report (Tipps et al., 2018), chemogenetic inhibition of BA principal neurons had no effect on time spent in the open or closed arms of the EPM $\left[t_{(20)}=1.378\right.$, $p=0.1834$ (open), $t_{(20)}=0.2696, p=0.7902$ (closed); unpaired Student's $t$ test; Fig. $3 D, E]$, or on total distance traveled during the test $\left(t_{(20)}=1.533, p=0.1409\right.$; unpaired Student's $t$ test; Fig. $3 F)$. Thus, chemogenetic inhibition of BA principal neurons, like optogenetic inhibition of BLA principal neuron somata (Tye et al., 2011), does not impact innate avoidance behavior in male C57BL/6J mice.

We also used AAV8-based vectors harboring the mDlx promoter/enhancer, which drives transgene expression in forebrain GABA neurons (Dimidschstein et al., 2016), to target inhibitory/GABA neurons in the BA. To evaluate the fidelity of AAV8/mDlx-based vectors in this structure, we infused AAV8-mDlx-mCherry into the BA of GAD67GFP(+) mice (Fig. 3G; Tamamaki et al., 2003). We observed a $72 \%$ overlap in GFP labeling and mCherry fluorescence, with $22 \%$ of cells expressing GFP alone (likely uninfected cells) and 6\% of cells expressing mCherry alone (Fig. 3H,I). Thus, AAV8/ $\mathrm{mDlx}$-based vectors afford relatively selective genetic access to the majority of GABA neurons in the BA. Unfortunately, chemogenetic inhibition of GABA neurons in the BA provoked mild-to-severe seizure activity in all subjects, precluding an evaluation of the impact of GABA neuron inhibition on innate avoidance behavior.

\section{Impact of chemogenetic inhibition of vHPC excitatory and GABA neurons on innate avoidance behavior} AAV8-CaMKII $\alpha$-hM4Di(mCherry) has been used to drive hM4Di expression in excitatory neurons of the vHPC, and chemogenetic inhibition of excitatory neurons throughout the vHPC decreased innate avoidance behavior in C57BL/6 mice (Parfitt et al., 2017). With optimization of targeting coordinates and viral loads, we were able to restrict the scope of viral infection to either CA1 (Fig. 4A,B) or CA3/DG (Fig. 4H,I) subregions of the vHPC. To assess the targeting fidelity of AAV8/CaMKII $\alpha$ vectors, we infused AAV8-CaMKII $\alpha$-mCherry into vCA1 or vCA3/DG subregions of GAD67GFP $(+)$ mice. We detected strong viral-driven mCherry fluorescence and minimal overlap with GFP-positive (GABA) neurons in both CA1 (Fig. 4C) and CA3/DG (Fig. 4J). Thus, AAV8/CaMKII $\alpha$ vectors afford genetic access to excitatory neurons in CA1 and CA3/DG subregions of the mouse vHPC.

We next treated adult male C57BL/6J mice with AAV8CaMKII $\alpha$-hM4Di(mCherry) or AAV8-CaMKII $\alpha$-mCherry control vector, targeting vCA1 or vCA3/DG. In slice electrophysiological validation studies, $\mathrm{CNO}$ increased the rheobase of hM4Di-expressing, but not mCherry control-expressing, CA1 pyramidal neurons $\left(t_{(5)}=5.456,{ }^{* *} p=0.0025\right.$; unpaired Student's $t$ test with Welch's correction; Fig. $4 D$ ), CA3 pyramidal neurons $t_{(3)}=3.749,{ }^{*} p=0.0305$; unpaired Student's $t$ test with Welch's 
A

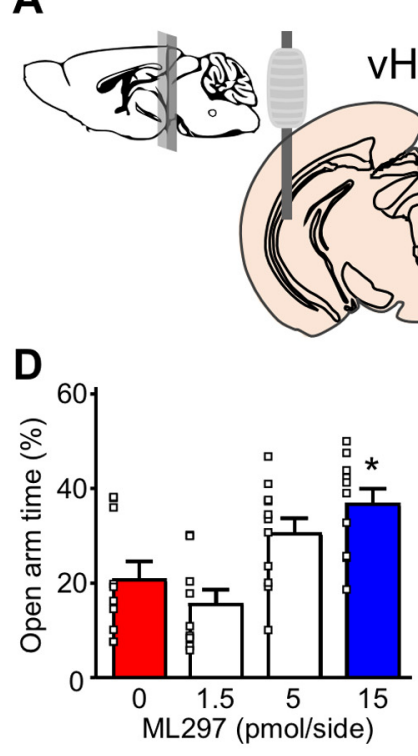

B

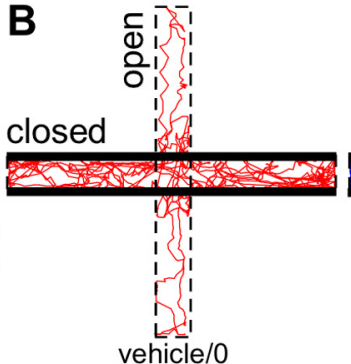

vehicle/0

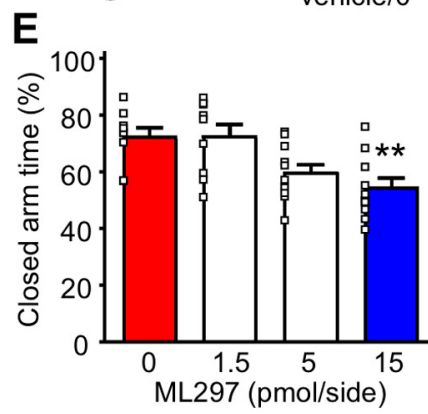

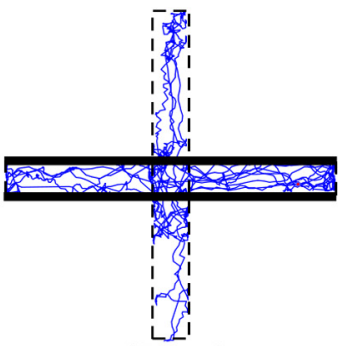

$15 \mathrm{pmol}$

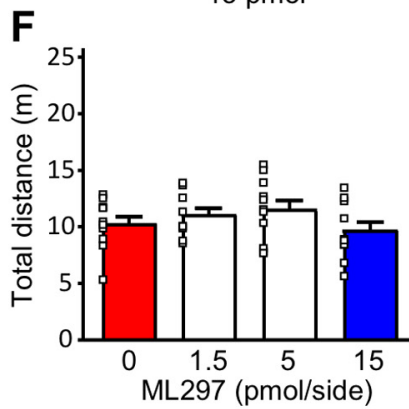

C $\bigcirc 15$

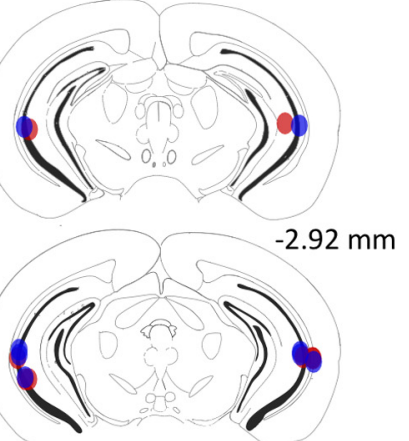

$-3.16 \mathrm{~mm}$

G

H

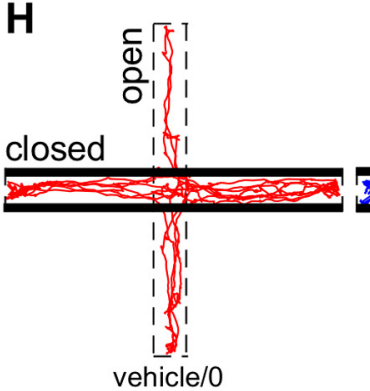

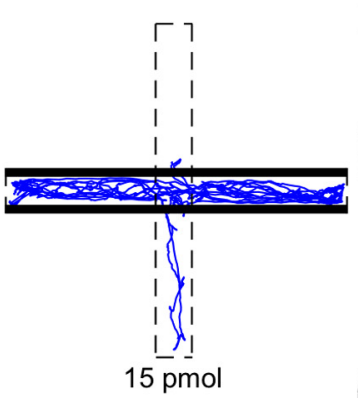

$15 \mathrm{pmol}$
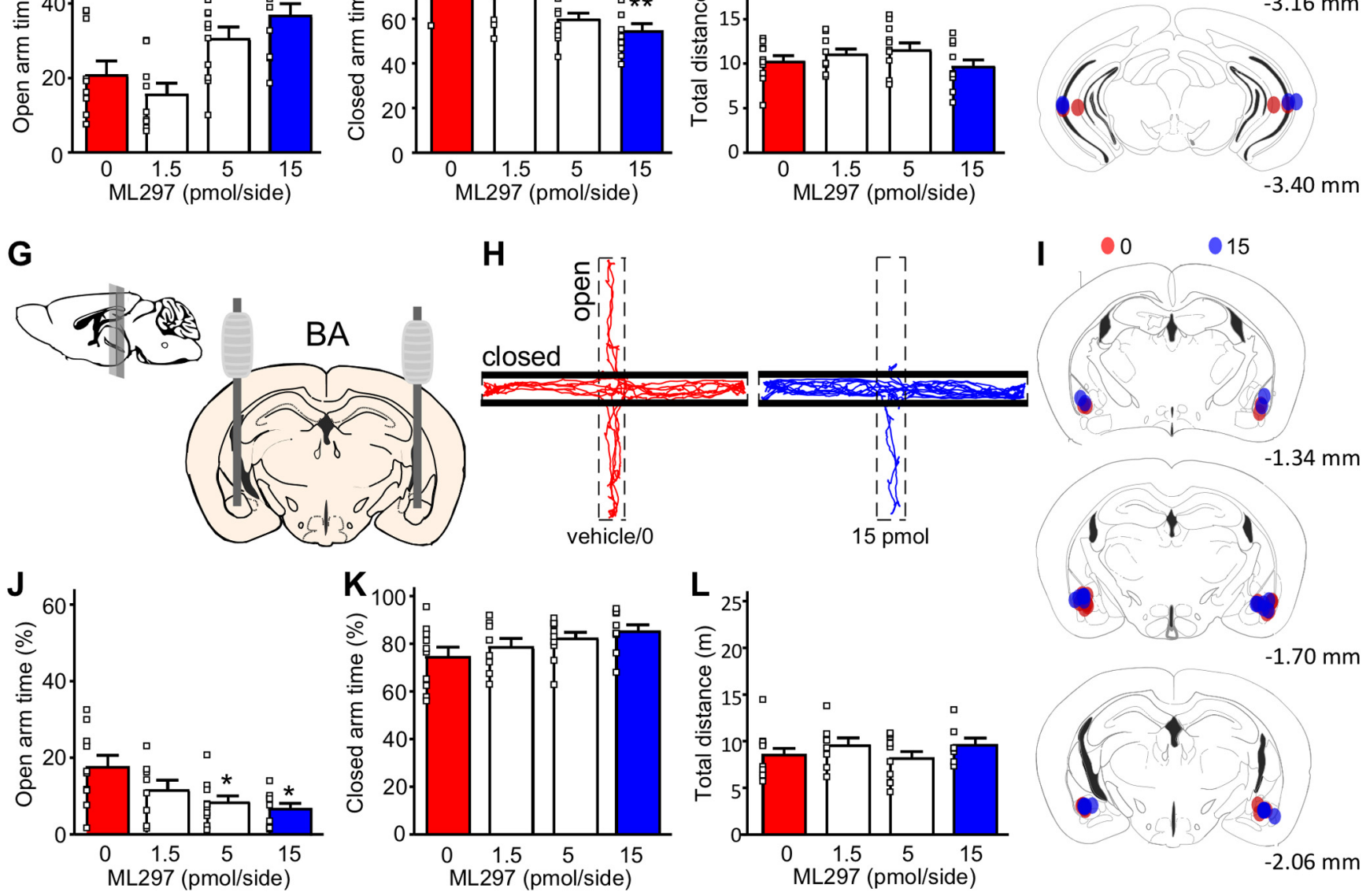

$-3.40 \mathrm{~mm}$

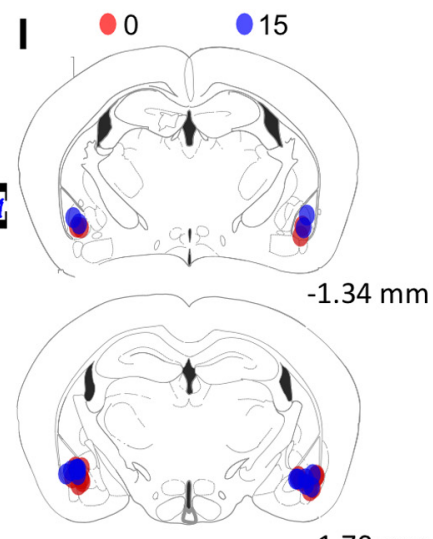

$-1.70 \mathrm{~mm}$

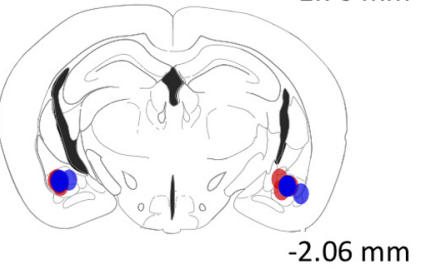

Figure 2. Impact of intracranial ML297 on EPM performance. A, Schematic of stereotaxic implantation of guide cannulae into the vHPC. Mice were allowed to recover from surgery for 7-9 $\mathrm{d}$ before behavioral testing. $\boldsymbol{B}$, Representative track plots of mice treated with intra-vHPC vehicle (0/left/red) or $15 \mathrm{pmol} / \mathrm{side}$ ML297 (right/blue) in the EPM test. C, Summary of cannulae placements, with colors representing individual subjects treated with vehicle/0 (red, $N=10$ ) or 15 (blue, $N=10$ ) pmol/side ML297. $\boldsymbol{D}, \boldsymbol{E}$, Percentage of time spent in the open $\left(F_{(3,36)}=7.36\right.$, $p=0.0006$; one-way ANOVA) and closed $\left(F_{(3,36)}=4.52, p=0.0086\right.$; one-way ANOVA) arms of the EPM following intra-vHPC infusion of ML297; ${ }^{*} p<0.05$ and ${ }^{* *} p<0.01$, respectively, versus $0 \mathrm{pmol}\left(N=9-11\right.$ mice/group). $\boldsymbol{F}$, Total distance traveled during the EPM test $\left(F_{(3,36)}=1.20, p=0.325\right.$; one-way ANOVA). $\boldsymbol{G}$, Schematic for stereotaxic implantation of guide cannulae into the BA. $\boldsymbol{H}$, Representative track plots of mice treated with intra-BA vehicle (0/left/red) or $15 \mathrm{pmol} /$ side ML297 (right/blue) in the EPM test. $\boldsymbol{I}$, Summary of cannulae placements, with colors representing individual subjects treated with vehicle/0 (red, $N=10$ ) and 15 (blue, $N=10$ ) pmol/side ML297. $\boldsymbol{J}, \boldsymbol{K}$, Percentage of time spent in the open $\left(F_{(3,34)}=4.047, p=0.0146 ;\right.$ one-way ANOVA) and closed $\left(F_{(3,34)}=1.813, p=0.1633\right.$; one-way ANOVA) arms of the EPM following intra-BA infusion of ML297; ${ }^{*} p<0.05$ versus 0 pmol $(N=8-10$ mice/group). $L$, Total distance traveled during the EPM test $\left(F_{(3,34)}=1.198, p=0.3252\right.$; one-way ANOVA).

correction; Fig. $4 K)$, and DG granule cells $\left(t_{(6.5)}=7.298\right.$, ${ }^{* *} p=0.0002$; unpaired Student's $t$ test with Welch's correction; Fig. $4 K)$. Chemogenetic inhibition of vCA1 pyramidal neurons had no impact on time spent in the open or closed arms of the $\mathrm{EPM}\left[t_{(17)}=0.8167, p=0.4254\right.$ (open), $t_{(17)}=1.557, p=0.1378$ (closed); unpaired Student's $t$ test; Fig. $4 E, F]$, or on total distance traveled during testing $\left(t_{(17)}=0.09228, p=0.9276\right.$; unpaired Student's $t$ test; Fig. $4 G$ ). In contrast, chemogenetic inhibition of vCA3/DG excitatory neurons increased time spent in the open arms of the EPM at the expense of time spent in the closed arms $\left[t_{(14.84)}=3.074,{ }^{* *} p=0.0078\right.$ (open), $t_{(17)}=3.228,{ }^{* *} p=0.0049$ (closed); unpaired Student's $t$ test with Welch's correction; Fig. $4 L, M]$, but did not impact total distance traveled $\left(t_{(17)}=1.185\right.$, $p=0.2523$; unpaired Student's $t$ test; Fig. $4 N$ ). Notably, these behavioral outcomes were recapitulated using a complementary approach involving the CaMKIICre $(+)$ transgenic driver line and Cre-dependent viral vectors $\left[t_{(15)}=0.3685, p=0.7177\right.$ (vCA1: open), $t_{(15)}=0.3007, p=0.7678$ (vCA1: closed), $t_{(15)}=$ 0.3286, $p=0.7470$ (vCA1: total distance), $t_{(13)}=3.153$, ${ }^{* *} p=0.0076$ (vCA3/DG: open), $t_{(13)}=2.795,{ }^{*} p=0.0152(\mathrm{vCA} 3 /$ 
A

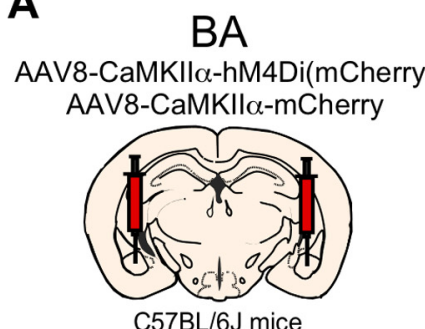

G

BA

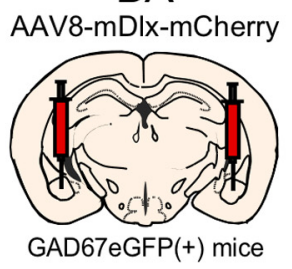

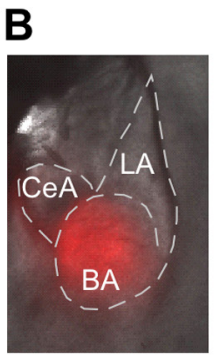

H

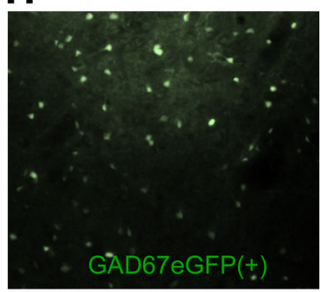

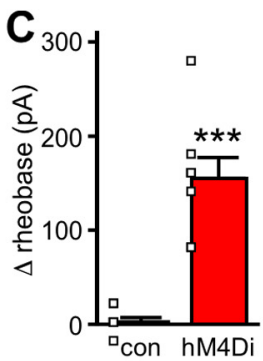

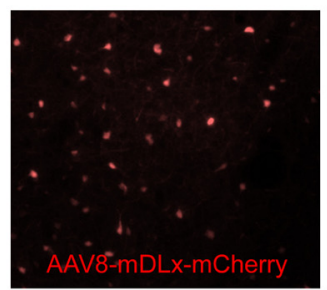

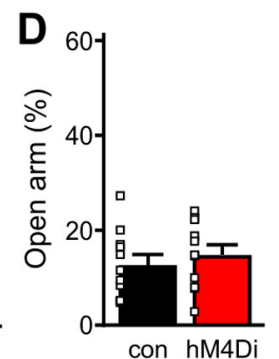
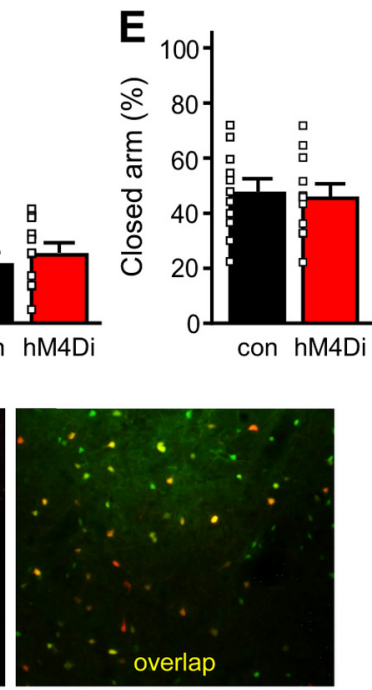
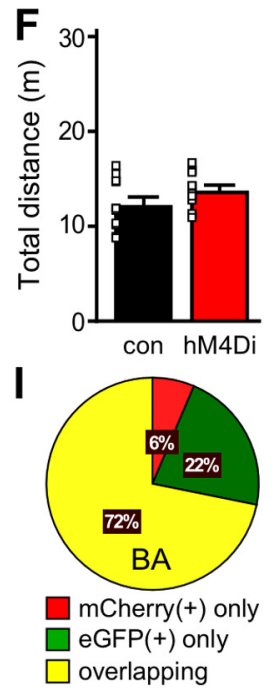

Figure 3. Chemogenetic inhibition of BA principal and GABA neurons. $A$, Schematic of bilateral targeting of the BA in male C57BL/6J mice with AAV8-CaMKIl $\alpha$-hM4Di(mCherry) or AAV8CaMKII $\alpha$-mCherry vectors. $\boldsymbol{B}$, Representative image of viral fluorescence in the BA, showing minimal spread into the LA and CeA. $\boldsymbol{C}$, Change in rheobase induced by CNO (10 $\mu \mathrm{m}$ ) in control or hM4Di-expressing BA principal neurons $\left(t_{(7.578)}=6.707,{ }^{* * *} p=0.0002\right.$; unpaired Student's $t$ test with Welch's correction; $N=2-3$ mice and $n=8$ total recordings/group). $\boldsymbol{D}, \boldsymbol{E}$, Percentage of time spent in open $\left(t_{(20)}=1.378, p=0.1834\right.$; unpaired Student's $t$ test) and closed ( $t_{(20)}=0.2696, p=0.7902$; unpaired Student's $t$ test) arms of the EPM by male C57BL/6J mice treated with intra-BA hM4Di or control vector $\left(N=11\right.$ mice/group), following administration of CNO $\left(2 \mathrm{mg} / \mathrm{kg}\right.$, i.p.). $\boldsymbol{F}$, Total distance traveled during the EPM test $\left(t_{(20)}=1.533, p=0.1409 ;\right.$ unpaired Student's $t$ test) by male (57BL/6J mice treated with hM4Di or control vector ( $N=11$ mice/group). G, Schematic of bilateral targeting of the BA in GAD67eGFP(+) mice with AAV8-mDlxmCherry. $\boldsymbol{H}$, Representative image of AAV8-mDlx-mCherry labeling in the BA of GAD67GFP(+) mouse. Left, eGFP(+) GABA neurons within the area of viral infusion. Middle, mDlx-driven mCherry expression in BA GABA neurons. Right, Overlap of GFP and mCherry fluorescence. $I$, Pie chart summarizing the quantification of percentages of neurons that are mCherry $(+)$ only,

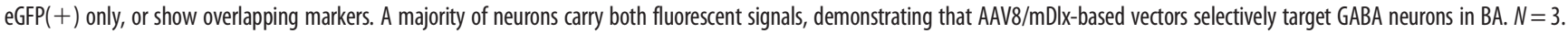

DG: closed), $t_{(13)}=0.8588, p=0.4060$ (vCA3/DG: total distance); unpaired Student's $t$ test; Fig. $4 E-G, L-N]$.

Chemogenetic inhibition of vCA3/DG excitatory neurons also increased time spent in the field center during the open-field test $\left(t_{(18)}=2.327,{ }^{\star} p=0.0318\right.$; Fig. $\left.4 O\right)$ and the light chamber in the light-dark test $\left(t_{(18)}=2.767,{ }^{*} p=0.0127\right.$; Fig. $\left.4 P\right)$, but this manipulation had no impact on marble-burying behavior $\left(t_{(18)}=\right.$ $1.790, p=0.0903$; Fig. 4Q). Since ML297 was previously characterized in EPM but not other tests of innate avoidance behavior (Wydeven et al., 2014; Vo et al., 2019), we sought to understand the involvement of ML297 in these behavioral models. Systemic ML297 administration also reduced avoidance behavior observed in the light-dark test $\left(t_{(22)}=2.198,{ }^{\star} p=0.0387\right.$; Fig. $\left.4 P\right)$, but had no effect in open-field $\left(t_{(22)}=0.1919, p=0.8496\right.$; Fig. $\left.4 O\right)$ or marble-burying tests $\left(t_{(22)}=0.4238, p=0.6758\right.$; Fig. $\left.4 Q\right)$. Thus, systemic ML297 administration in male C57BL/6J mice is sufficient to recapitulate the impact of acute chemogenetic inhibition of excitatory neurons in the vHPC CA3/DG subregion in EPM and light-dark tests, but not open-field test; the impact of both manipulations on avoidance behavior was most pronounced in the EPM test.

To interrogate the behavioral impact of selective inhibition of defined neuron populations in the vHPC, we combined Cre-dependent viral vectors with Cre-driver lines affording access to CA1 (TrpC4Cre; Okuyama et al., 2016; Fig. 5A,B) and CA3 (Grik4Cre; Nakazawa et al., 2002; Fig. 5F,G) pyramidal neurons, and DG granule cells (DOCK10Cre; Kohara et al., 2014; Fig. $5 K, L)$. Consistent with results described above, we observed no significant impact of chemogenetic inhibition of vCA1 pyramidal neurons on EPM performance $\left[t_{(15)}=1.22, p=0.240\right.$ (open), $t_{(15)}=1.10, p=0.287$ (closed), $t_{(15)}=0.042, p=0.967$ (total distance); unpaired Student's $t$ test; Fig. 5C-E]. Similarly, neither the selective inhibition of vCA3 pyramidal neurons $\left[t_{(13)}=1.57\right.$, $p=0.141$ (open), $t_{(13)}=1.64, p=0.125$ (closed), $t_{(13)}=1.69$, $p=0.114$ (total distance); unpaired Student's $t$ test; Fig. $5 H-J$ ], nor the selective inhibition of vDG granule cells $\left[t_{(17)}=0.048\right.$, $p=0.963$ (open), $t_{(17)}=0.83, p=0.417$ (closed), $t_{(17)}=1.35$, $p=0.195$ (total distance); unpaired Student's $t$ test; Fig. 5M-O], significantly impacted EPM performance. These results suggest that combined inhibition of excitatory neurons in vCA3/DG is required to suppress innate avoidance behavior in male mice.

We also targeted inhibitory/GABA neurons in the vHPC with AAV8/mDlx-based vectors. We infused AAV8-mDlx-mCherry into the vHPC of GAD67GFP( $(+)$ mice (Fig. 5P), and found that $70 \%$ of neurons exhibited GFP and mCherry fluorescence, while $19 \%$ expressed GFP alone (likely uninfected cells) and 11\% expressed mCherry alone (Fig. 5Q,R). Thus, AAV8/mDlx-based vectors afford relatively selective genetic access to the majority of GABA neurons in the vHPC. Unfortunately, chemogenetic inhibition of GABA neurons in the vHPC provoked severe seizure activity in all subjects, resulting in death of most subjects tested.

\section{Impact of GIRK channel ablation in vCA3/DG excitatory neurons on systemic ML297}

To test whether the combined GIRK-dependent inhibition of excitatory neurons in CA3/DG subregion of the vHPC mediates the impact of systemic ML297 on EPM performance in mice, we employed a viral Cre strategy to ablate GIRK channels selectively in this vHPC subregion. We infused AAV8-CaMKII $\alpha$-Cre (mCherry) or AAV8-CaMKII $\alpha$-mCherry into vCA3/DG of male Girk $1^{f l / f l}$ mice (Fig. 6A). In both vCA3 pyramidal (Fig. 6B) and vDG granule cells (Fig. 6C) from Girk $1^{f l / f l}$ mice, Cre treatment decreased the amplitude of baclofen-induced somatodendritic currents $\left[t_{(9.9)}=9.499,{ }^{* * * *} p<0.0001(\mathrm{vCA} 3), t_{(16)}=5.403\right.$, ${ }^{* * * *} p<0.0001$ (vDG); unpaired Student's $t$ test; Fig. $6 D$ ], a composite $\mathrm{GABA}_{\mathrm{B}}$ receptor-dependent response mediated primarily by GIRK channel activation (Lüscher et al., 1997; Koyrakh et al., 2005). Loss of GIRK channel activity in these neurons also decreased rheobase $\left[t_{(14)}=4.234,{ }^{* *} p=0.0008(\mathrm{vCA} 3), t_{(18)}=\right.$ 
A

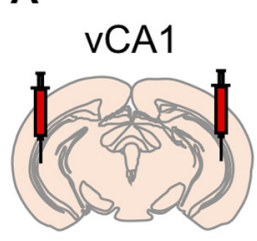

E

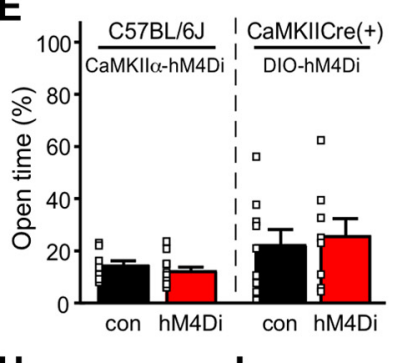

H

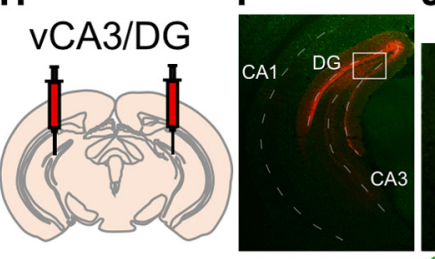

L

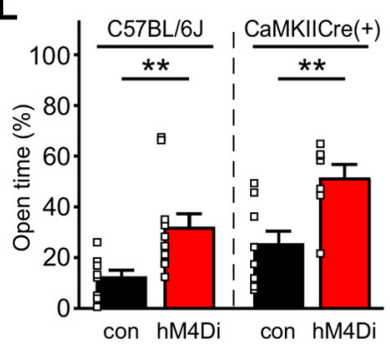

0

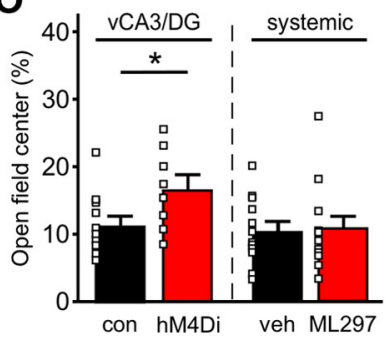

B
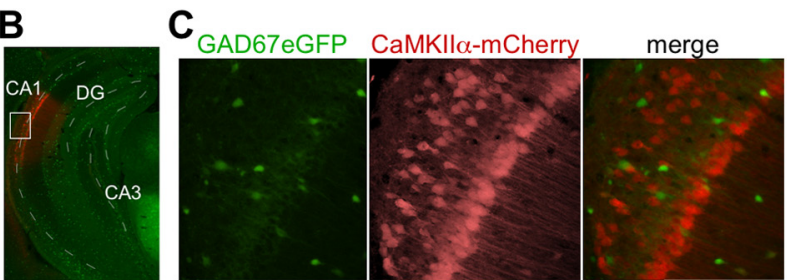

F

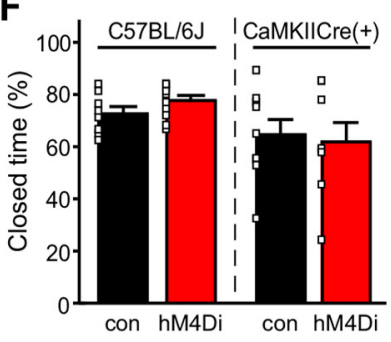

G
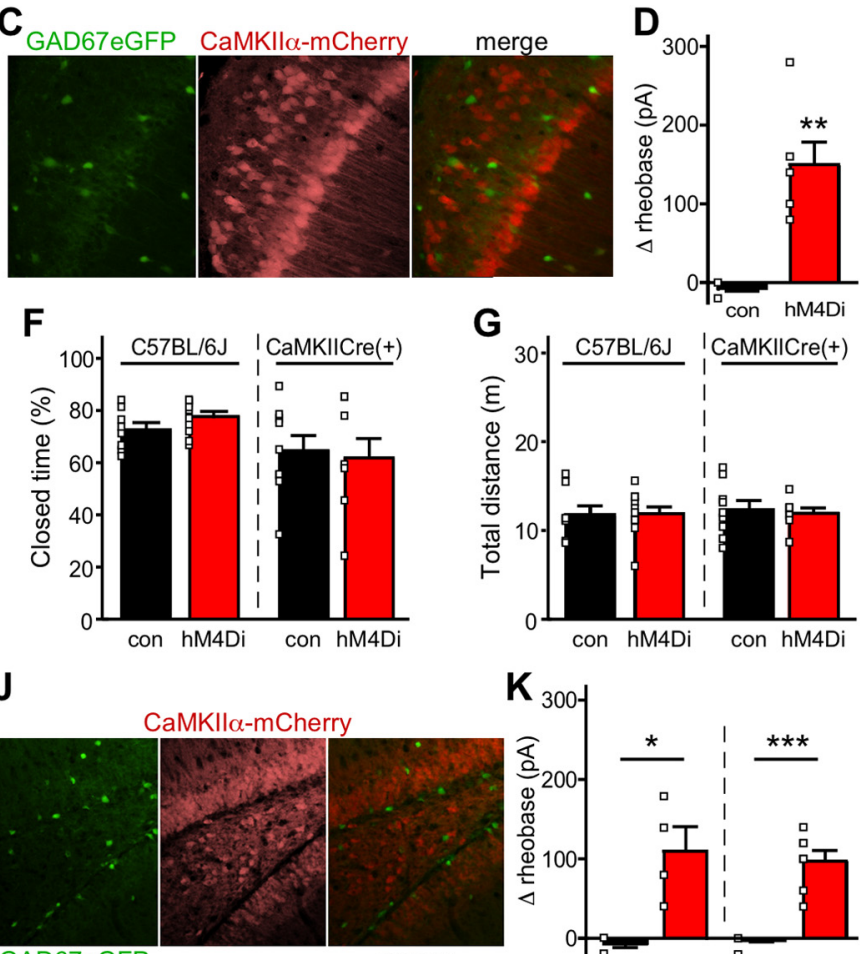

GAD67eGFP

merge

M

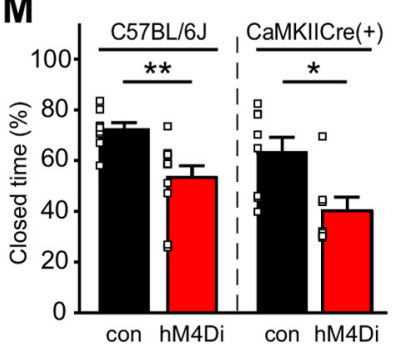

P

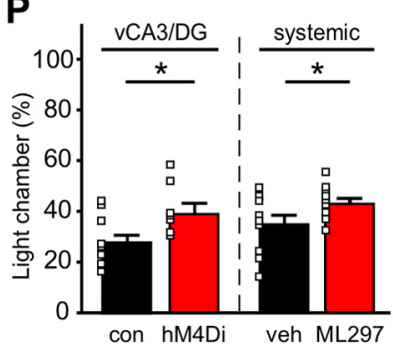

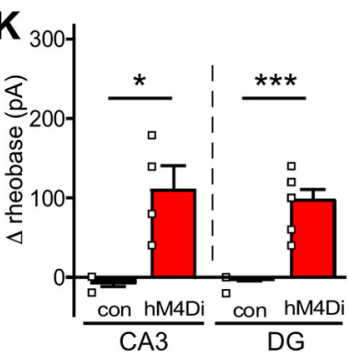

N

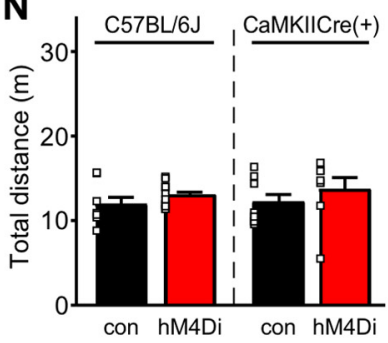

Q

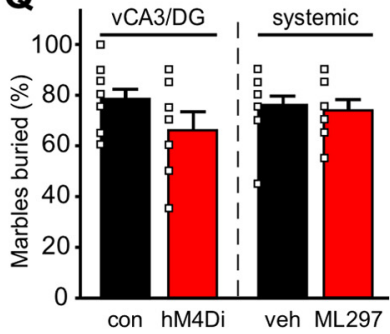

Figure 4. Chemogenetic inhibition of excitatory neurons in the mouse VHPC. $A$, Schematic of bilateral targeting of VCA1. $B$, Representative image of the vHPC from a GAD67GFP( + ) mouse receiving AAV8-CaMKII $\alpha$-mCherry in vCA1. Dashed lines highlight vCA1, vCA3, and vDG subregions. The white rectangle shows the area enlarged in panel $C$. $C$, Image of the vCA1 subregion

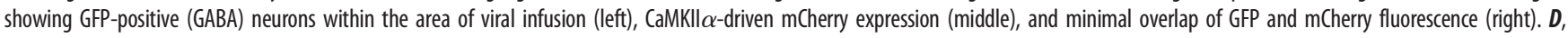
Change in rheobase induced by CNO $(10 \mu \mathrm{m})$ in control or hM4Di-expressing vCA1 pyramidal neurons $\left(t_{(5)}=5.456,{ }^{* *} p=0.0025\right.$; unpaired Student's $t$ test with Welch's correction; $N=2$ mice and $n=6-8$ total recordings/group). $\boldsymbol{E}, \boldsymbol{F}$, left, Percentage of time spent in open $\left(t_{(17)}=0.8167, p=0.4254\right.$; unpaired Student's $t$ test) and closed $\left(t_{(17)}=1.557, p=0.1378 ;\right.$ unpaired Student's $t$ test) arms of the EPM by male C57BL/6J mice treated with intra-vCA1 hM4Di or control vector ( $N=8-11$ mice/group), following administration of CNO (2 mg/kg, i.p.). Right, Percentage of time spent in open $\left(t_{(15)}=0.3685, p=0.7177\right.$; unpaired Student's $t$ test) and closed ( $t_{(15)}=0.3007, p=0.7678$; unpaired Student's $t$ test) arms of the EPM by male CaMKIICre (+) mice treated with intra-vCA1 AAV8-hSyn-DI0-hM4Di(mCherry) or AAV8-hSyn-DI0-mCherry vector (N=8-9 mice/group), following administration of CNO ( $2 \mathrm{mg} / \mathrm{kg}$, i.p.). G, Total distance traveled during the EPM test by male C57BL/6J mice treated with hM4Di or control vector (left, $t_{(17)}=0.09228, p=0.9276$; unpaired Student's $t$ test), and in CaMKIICre( + ) mice treated with intra-vCA1 DI0-hM4Di or control vector (right, $t_{(15)}=0.3286, p=0.7470$; unpaired Student's $t$ test). $\boldsymbol{H}$, Schematic of bilateral targeting of vCA3/DG. I, Representative image of the vHPC from a GAD67GFP $(+)$ mouse receiving AAV8-CaMKII $\alpha$-mCherry in the vCA3/DG subregion. The white open box shows the area enlarged in panel J. J, Image of the vCA3/DG subregion showing GFPpositive (GABA) neurons within the area of viral infusion (left), CaMKll $\alpha$-driven mCherry expression (middle), and minimal overlap of GFP and mCherry fluorescence (right). $\boldsymbol{K}$, left, Change in rheobase induced by CNO $(10 \mu \mathrm{M})$ in control or hM4Di-expressing vCA3 pyramidal neurons $\left(t_{(3)}=3.749,{ }^{*} p=0.0305\right.$; unpaired Student's $t$ test with Welch's correction; $N=1-2$ mice and $n=4-5$ total recordings/group). Right, Change in rheobase induced by CNO $(10 \mu \mathrm{M})$ in control or hM4Di-expressing vDG granule cells $\left(t_{(6.5)}=7.298,{ }^{* * *} p=0.0002 ;\right.$ unpaired Student's $t$ test with Welch's correction; $N=2$ mice and $n=7$ total recordings/group). $L, M$, left, Percentage of time spent in open $\left(t_{(14.84)}=3.074,{ }^{* *} p=0.0078\right.$; unpaired Student's $t$ test with Welch's correction) and closed $\left(t_{(17)}=3.228,{ }^{* *} p=0.0049\right.$; unpaired Student's $t$ test) arms of the EPM by male C57BL/6J mice treated with intra-vCA3/DG hM4Di or control vector (N=8-11 mice/group), following administration of CNO (2 mg/kg, i.p.). Right, Percentage of time spent in open $\left(t_{(13)}=3.153,{ }^{* *} p=0.0076\right.$; unpaired Student's $t$ test) and closed $\left(t_{(13)}=2.795\right.$, ${ }^{*} p=0.0152 ;$ unpaired Student's $t$ test) arms of the EPM by male CaMKIICre(+) mice treated with intra-vCA3/DG DI0-hM4Di or control vector ( $N=7-8$ mice/group), following administration of CNO (2 mg/kg, i.p.). 
3.773, ${ }^{* *} p=0.0014$ (vDG); unpaired Student's $t$ test; Fig. $\left.6 E\right]$, consistent with an increase in excitability, but did not impact resting membrane potential $\left[t_{(16)}=1.155, p=0.2652\right.$ (vCA3), $t_{(18)}=0.6257, p=0.5394$ (vDG); unpaired Student's $t$ test; Fig. $6 F$. Importantly, GIRK channel ablation in vCA3/DG excitatory neurons precluded the increase in time spent in the open arms $[t=1.142, p=0.2715$ (Cre/Veh vs Cre/ML297), $t=3.051,{ }^{* *} p=0.0076$ (Cre/ML297 vs mCherry/ML297); unpaired Student's $t$ test; Fig. $6 G$ ] and decrease in time spent in the closed arms $[t=1.581, p=0.1348$ (Cre/Veh vs Cre/ML297), $t=3.317,{ }^{*} p=0.0047$ (Cre/ML297 vs mCherry/ ML297); unpaired Student's $t$ test; Fig. $6 H$ ] evoked by systemic ML297, without impacting total distance traveled during EPM testing $[t=0.7080, p=0.4921$ (Cre/Veh vs Cre/ML297), $t=2.005$, $p=0.0603$ (Cre/ML297 vs mCherry/ML297); unpaired Student's $t$ test; Fig. 6I]. Thus, GIRK channel activation in excitatory neurons in vCA3/DG is necessary for the suppression of innate avoidance behavior induced by systemic ML297 administration in male C57BL/6J mice.

\section{Discussion}

Both constitutive ablation (Blednov et al., 2001; Pravetoni and Wickman, 2008) and acute pharmacological activation (Wydeven et al., 2014) of GIRK channels correlate with decreased innate avoidance behavior in mice. The similar behavioral outcomes for both gain-of-function and loss-of-function manipulations of GIRK channel activity suggested the presence of complex, opposing contributions of neuronal GIRK channel activity on innate avoidance behavior. Subsequent genetic manipulations ablating GIRK channels selectively in GABA neurons or forebrain excitatory neurons, however, had no impact on EPM performance (Victoria et al., 2016). Here, we identify discrete limbic structures that could help explain the complex influence of GIRK channels on innate avoidance behavior in mice. Specifically, we show that acute pharmacological activation of GIRK channels in the vHPC and BLA complex exerts opposing influence on innate avoidance behavior in male mice.

The impact of GIRK channel activation in vHPC on innate avoidance behavior aligns with the effect of systemic ML297, and GIRK channel ablation in vCA3/DG excitatory neurons precluded the efficacy of systemic ML297. Conversely, acute activation of GIRK channels in the BA increased avoidance behavior. Collectively, our observations suggest that the behavioral impact

\footnotetext{
$\leftarrow$

N, Total distance traveled during the EPM test by male C57BL/6J mice treated with hM4Di or control vector (left, $t_{(17)}=1.185, p=0.2523$; unpaired Student's $t$ test) and in male CaMKIIICre(+) mice treated with intra-vCA1 DI0-hM4Di or control vector (right, $t_{(13)}=$ $0.8588, p=0.4060$; unpaired Student's $t$ test). $\mathbf{0}$, left, Percentage of time spent in open-field center by male $557 \mathrm{BL} / 6 \mathrm{~J}$ mice treated with hM4Di or control vector $\left(t_{(18)}=2.327\right.$, ${ }^{*} p=0.0318$; unpaired Student's $t$ test), following administration of CNO (2 mg/kg, i.p.). Right, Percentage of time spent in open-field center by male $557 \mathrm{BL} / 6 \mathrm{~J}$ mice treated with systemic ML297 (30 mg/kg, i.p.) or vehicle $\left(t_{(22)}=0.1919, p=0.8496\right.$; unpaired Student's $t$ test) $30 \mathrm{~min}$ before testing. $\boldsymbol{P}$, left, Percentage of time spent in light chamber of light-dark box by male $\left[57 \mathrm{BL} / 6 \mathrm{~J}\right.$ mice treated with hM4Di or control vector $\left(t_{(18)}=2.767,{ }^{*} p=0.0127\right.$; unpaired Student's $t$ test), following administration of CNO ( $2 \mathrm{mg} / \mathrm{kg}$, i.p.). Right, Percentage of time spent in light chamber by male C57BL/6J mice treated with systemic ML297 (30 mg/ $\mathrm{kg}$, i.p.) or vehicle $\left(t_{(22)}=2.198,{ }^{*} p=0.0387\right.$; unpaired Student's $t$ test) 30 min before testing. $\mathbf{Q}$, left, Percentage of marbles buried by male $557 \mathrm{BL} / 6 \mathrm{~J}$ mice treated with $\mathrm{hM4Di}$ or control vector $\left(t_{(18)}=1.790, p=0.0903\right.$; unpaired Student's $t$ test), following administration of CNO $(2 \mathrm{mg} / \mathrm{kg}$, i.p.). Right, Percentage of marbles buried by male $(57 \mathrm{BL} / 6 \mathrm{~J}$ mice treated with systemic ML297 (30 mg/kg, i.p.) or vehicle $\left(t_{(22)}=0.4238, p=0.6758\right.$; unpaired Student's $t$ test) $30 \mathrm{~min}$ before testing.
}

of ML297-induced inhibition of vCA3/DG overrides the impact of ML297-induced inhibition of the BA. This could be explained in part by the amplitude of ML297-induced somatodendritic currents, which were notably larger in vCA3 pyramidal neurons than BA principal neurons. GIRK channels are expressed in other brain regions implicated in anxiety-related behavior, however, including the medial prefrontal cortex (Hearing et al., 2013), hypothalamus (Karschin et al., 1996), habenula (Lecca et al., 2016). Thus, the effect of systemic ML297 on EPM performance is likely shaped by GIRK-dependent inhibition in several brain regions.

Given that intra-BA ML297 provoked increased avoidance behavior in male mice, the lack of impact of chemogenetic inhibition of BA principal neurons on EPM performance was unexpected, particularly since chemogenetic inhibition of BA principal neurons is mediated largely by GIRK channel activation (Tipps et al., 2018). Nevertheless, our results mirror the outcome of optogenetic inhibition experiments targeting BLA principal neuron somata, which also did not impact EPM performance (Tye et al., 2011). ML297-induced GIRK channel activation may evoke a stronger inhibition of BA principal neurons than hM4Di activation, a contention supported by the observation that the impact of intra-BA ML297 on EPM performance was seen only at the highest dose administered. The differential impact of intra-BA ML297 and acute chemogenetic inhibition may also be attributable to the different scope of pharmacological and viral interventions. The LA and BA subregions of the BLA complex contribute in distinct fashion to fear-related behavior (Calhoon and Tye, 2015; Manassero et al., 2018; Tipps et al., 2018), and optical inhibition of principal neurons in the adjacent basomedial amygdala increased anxiety-related behavior in the open-field test (Adhikari et al., 2015). Although we targeted the BA in intracranial pharmacological and chemogenetic experiments, ML297 may diffuse further than AAV vectors, impacting adjacent structures.

The differential behavioral influence of discrete BLA projections may also contribute to the discrepant outcomes of the intracranial pharmacological and chemogenetic studies. Indeed, optogenetic stimulation of BLA principal neurons projecting to the central amygdala (CeA) suppressed innate avoidance behavior (Tye et al., 2011), whereas optogenetic stimulation of BLA projections to the vHPC and mPFC increased avoidance behavior (Felix-Ortiz et al., 2013, 2016). These findings suggest the intriguing possibility that the strength of GIRK-dependent signaling differs in BLA principal neurons in a projection-specific manner, with projections that normally suppress avoidance behavior (e.g., BLA-CeA projection; Tye et al., 2011) being particularly sensitive to ML297-induced inhibition.

While the vHPC has been implicated in innate avoidance behavior, the roles of specific vHPC subregions and neuron populations are less clear (Kheirbek et al., 2013; Weeden et al., 2015; Engin et al., 2016; Parfitt et al., 2017; Jimenez et al., 2018; Schumacher et al., 2018). The activity of vCA1 pyramidal neurons, the major output neurons of the vHPC (Basu and Siegelbaum, 2015), has been implicated in the expression of avoidance behavior. Most notably, the majority of mouse vCA1 pyramidal neurons exhibited increased intracellular $\mathrm{Ca}^{2+}$ activity during open arm exploration, and optogenetic silencing of these neurons on entry into the open arms decreased avoidance behavior (Jimenez et al., 2018). Furthermore, vCA1 projections to the lateral hypothalamic area and prefrontal cortex showed elevated activity in anxiogenic settings, and inhibition of these projections suppressed avoidance behavior (Ciocchi et al., 2015; PadillaCoreano et al., 2016; Jimenez et al., 2018). 
A

vCA1

AAV8-hSyn-DIO-hM4Di(mCherry)

AAV8-hSyn-DIO-mCherry

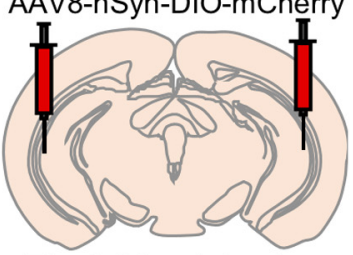

TrpC4Cre(+) mice

F

vCA3

AAV8-hSyn-DIO-hM4Di(mCherry) AAV8-hSyn-DIO-mCherry

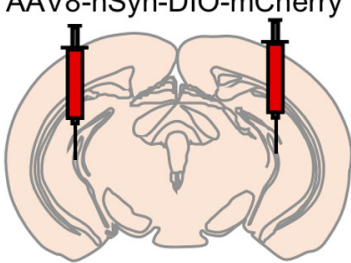

Grik4Cre(+) mice

K

VDG

AAV8-hSyn-DIO-hM4Di(mCherry) AAV8-hSyn-DIO-mCherry
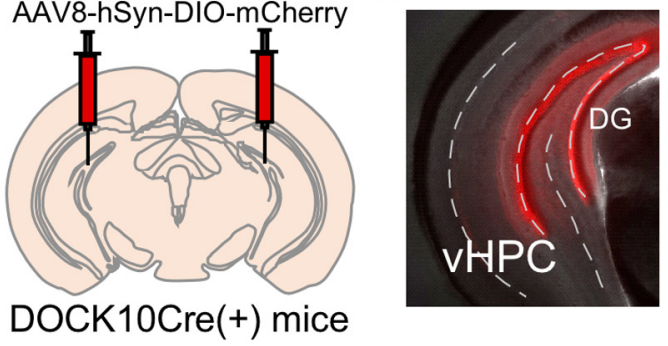

G

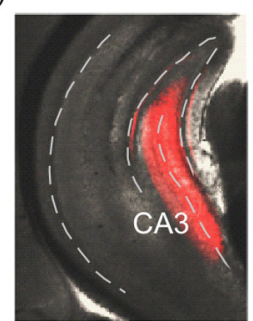

$\mathbf{L}$

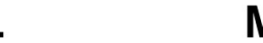

Q

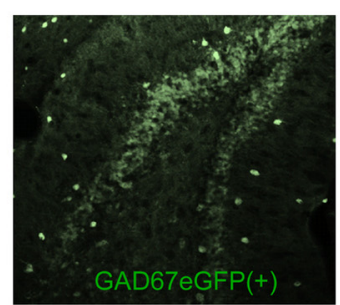

M

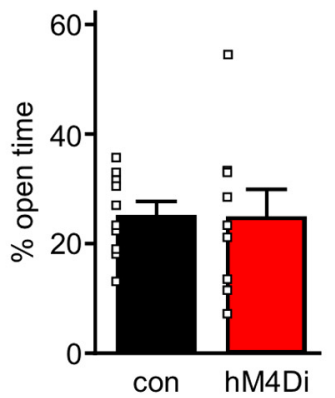

C

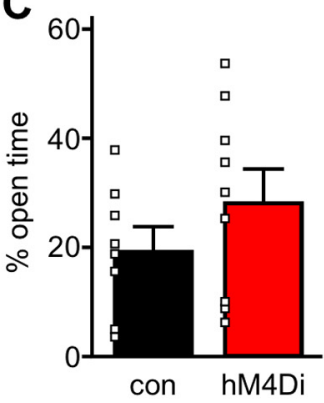

H

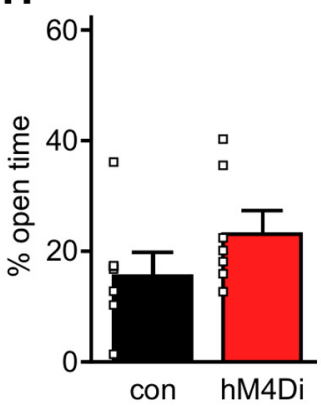

I

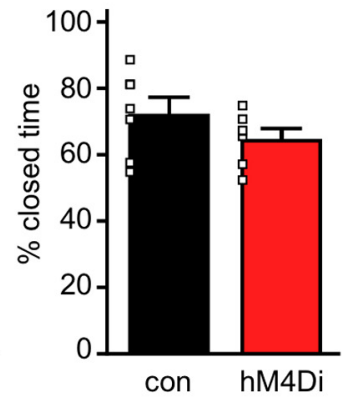

N
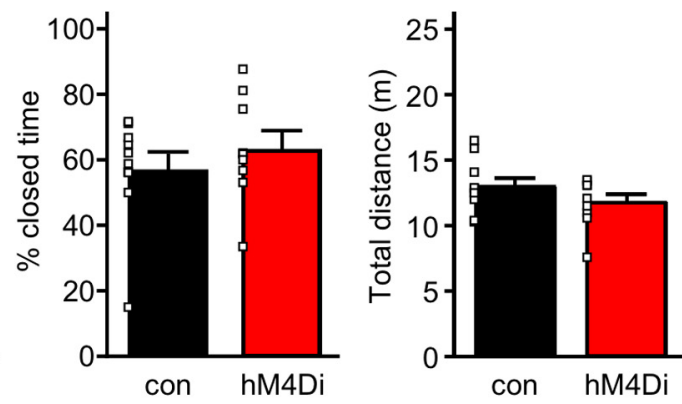

$\mathbf{R}$
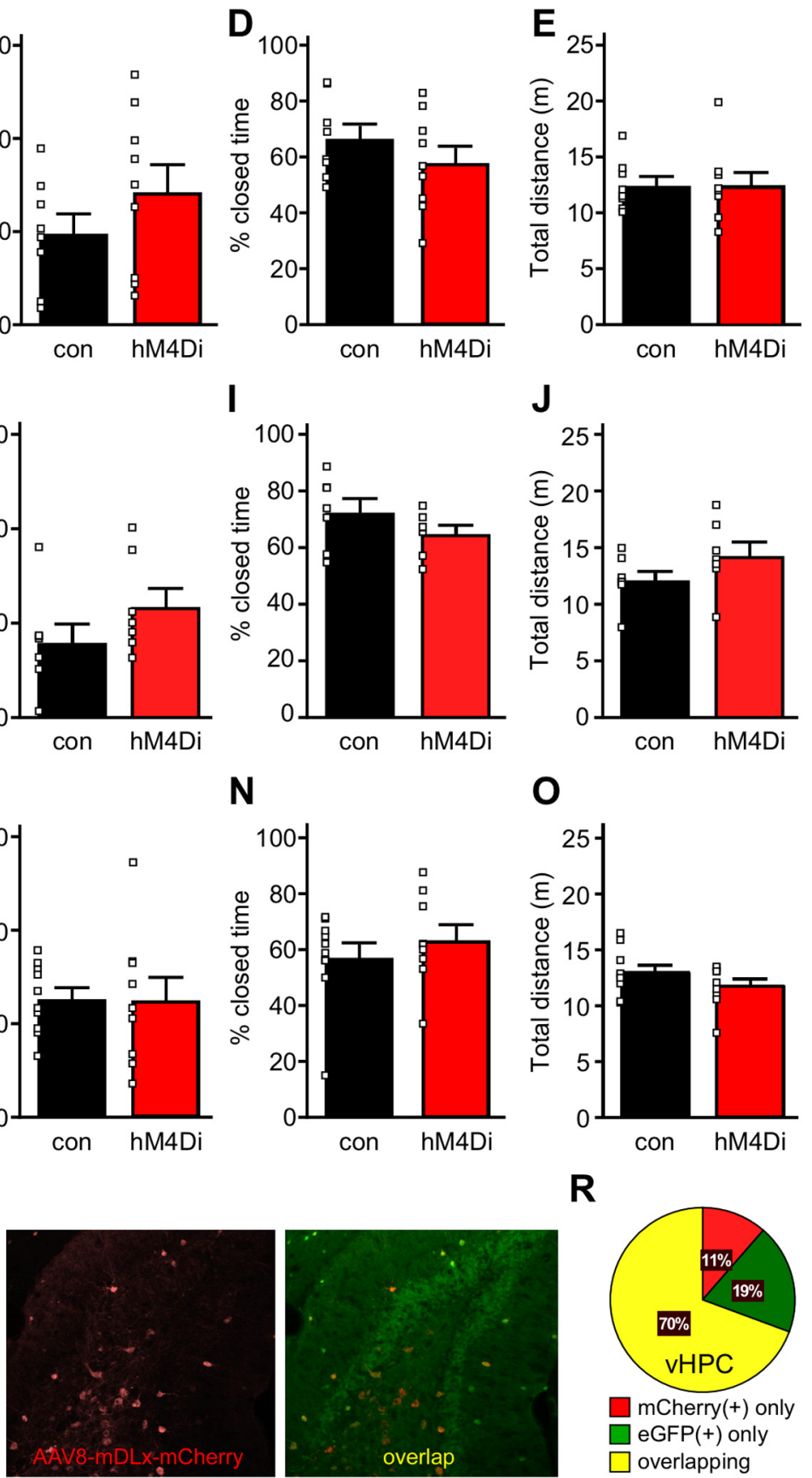

J

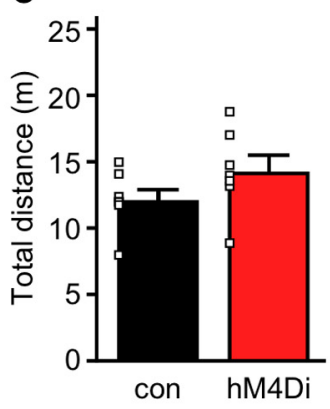

0
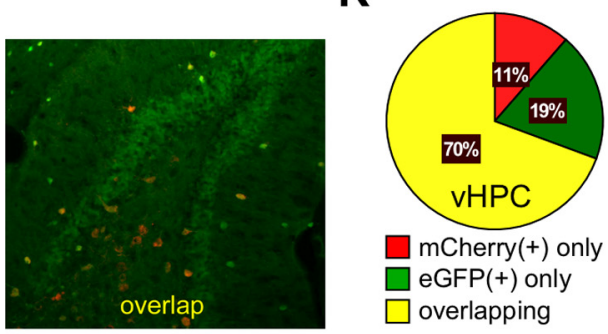

GAD67eGFP(+) mice

Figure 5. Chemogenetic inhibition of excitatory vCA1, vCA3, or vDG neurons. $A$, Schematic of bilateral targeting of vCA1 in TrpC4Cre(+) mice treated with either AAV8-hSyn-DI0-hM4Di (mCherry) or AAV8-hSyn-DI0-mCherry vector. B, Representative image of viral targeting of vCA1 pyramidal neurons in a TrpC4Cre(+) mouse treated with AAV8-hSyn-DI0-mCherry. C, D, Percentage of time spent in the open $\left(t_{(15)}=1.22, p=0.240\right.$; unpaired Student's $t$ test) and closed $\left(t_{(15)}=1.10, p=0.287\right.$; unpaired Student's $t$ test) arms for male TrpC4Cre $(+)$ mice treated with DI0-hM4Di or control vector $\left(N=8-9\right.$ mice/group). $\boldsymbol{E}$, Total distance traveled during the EPM test by male $\operatorname{Trp} C 4 \mathrm{Cre}(+)$ mice treated with DI0-hM4Di or DI0-control vector $\left(t_{(15)}=0.042\right.$, $p=0.967$; unpaired Student's $t$ test). $\boldsymbol{F}$, Schematic of bilateral targeting of vCA3 in Grik4Cre(+) mice treated with either AAV8-hSyn-DI0-hM4Di(mCherry) or AAV8-hSyn-DI0-mCherry vector. $\mathbf{G}$, Representative image of viral targeting of vCA3 pyramidal neurons in a Grik4Cre(+) mouse treated with AAV8-hSyn-DI0-mCherry. $\boldsymbol{H}, \boldsymbol{I}$, Percentage of time spent in the open $\left(t_{(13)}=1.57\right.$, $p=0.141$; unpaired Student's $t$ test) and closed $\left(t_{(13)}=1.64, p=0.125\right.$; unpaired Student's $t$ test) arms for male Grik4Cre $(+)$ mice treated with DI0-hM4Di or DI0-control vector $(N=7-8$ mice/group). J, Total distance traveled during the EPM test by male Grik4Cre(+) mice treated with DI0-hM4Di or DI0-control vector $\left(t_{(13)}=1.69, p=0.114\right.$; unpaired Student's $t$ test). $\boldsymbol{K}$, Schematic of bilateral targeting of VDG in DOCK10Cre(+) mice treated with either AAV8-hSyn-DI0-hM4Di(mCherry) or AAV8-hSyn-DI0-mCherry vector. L, Representative image of viral targeting of vDG granule cells in a DOCK10Cre(+) mouse treated with AAV8-hSyn-DI0-mCherry. $\boldsymbol{M}, \mathbf{N}$, Percentage of time spent in the open $\left(t_{(17)}=0.048, p=0.963\right.$; unpaired Student's $t$ test) and closed $\left(t_{(17)}=0.83, p=0.417\right.$; unpaired Student's $t$ test) arms for male DOCK10Cre $(+)$ mice treated with DI0-hM4Di or DI0-control vector ( $N=9-10$ mice/group). 0, Total distance traveled during the EPM test by male DOCK10Cre(+) mice treated with DI0-hM4Di or DI0-control vector $\left(t_{(17)}=1.35, p=0.195\right.$; unpaired Student's $t$ test). $P$, Schematic of bilateral targeting of the vHPC in GAD67eGFP(+) mice with AAV8-mDlx-mCherry. $\mathbf{Q}$, Representative image of AAV8-mDlx-mCherry labeling in the vHPC of GAD67GFP(+) mouse. Left, eGFP(+) GABA neurons within the area of viral infusion. Middle, mDlx-driven mCherry expression in vHPC GABA neurons. Right, Overlap of GFP and mCherry fluorescence. $\boldsymbol{R}$, Pie chart summarizing the quantification of percentages of neurons that are $\mathrm{mCherry}(+)$ only, $\mathrm{GFP}(+)$ only, or show overlapping markers. A majority of neurons carry both fluorescent signals, demonstrating that AAV8/mDlx-based vectors selectively target GABA neurons in vHPC. $N=4$. 
A
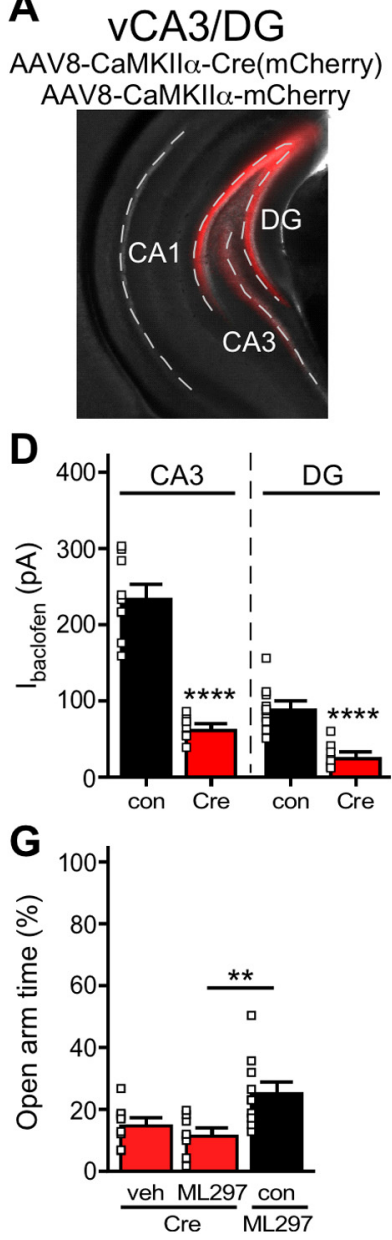

B

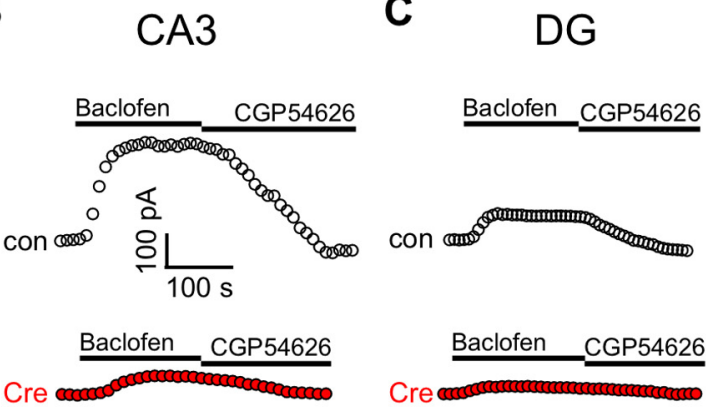

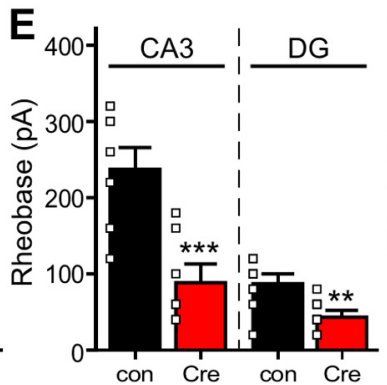

H

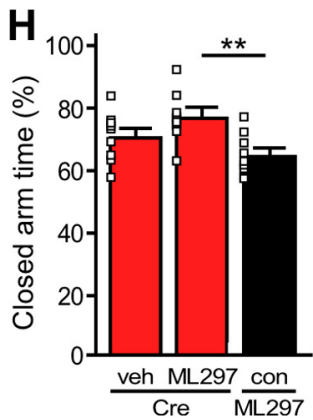

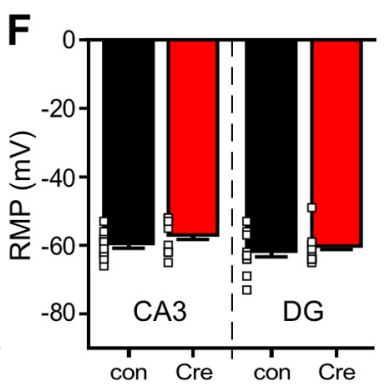

I

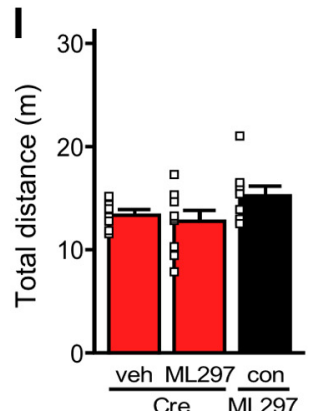

Figure 6. GIRK channel ablation in vCA3/DG and systemic ML297. $A$, Representative image of the vCA3/DG from a Girk $7^{f / f t}$ mouse receiving AAV8-CaMKII $\alpha$-mCherry in vCA3/DG. Dash lines highlight the vCA1, vCA3, and vDG subregions of vHPC. $\boldsymbol{B}$, C, Representative somatodendritic currents $\left(V_{\text {hold }}=-60 \mathrm{mV}\right)$ evoked by baclofen $(200 \mu \mathrm{m})$, and reversed by the $\mathrm{GABA}_{B}$ receptor antagonist CGP54626 (2 $\mu \mathrm{M})$, in vCA3 pyramidal and vDG neurons from Girk $7^{f / f f l}$ mice treated with AAV8-CaMKII $\alpha$-Cre (mCherry) or AAV8-CaMKII $\alpha$-mCherry vector. $\boldsymbol{D}$, Summary of baclofen-induced currents in vCA3 (left, $t_{(9.9)}=9.499$, ${ }_{* * * *}^{*}<0.0001$; unpaired Student's $t$ test with Welch's correction. $N=2-3$ mice and $n=7-9$ total recordings/group) and vDG (right, $t_{(16)}=5.403,{ }^{* * *} p<0.0001$; unpaired Student's $t$ test. $N=2-3$ mice and $n=8-10$ total recordings/group) excitatory neurons from Girk $7^{f / f f l}$ mice treated with intra-vCA3/DG AAV8-CaMKII $\alpha$-Cre(mCherry) or AAV8-CaMKII $\alpha$-mCherry vector. $\boldsymbol{E}$, Impact of Girk1 ablation on rheobase in vCA3 (left, $t_{(14)}=4.234,{ }^{* * *} p=0.0008$; unpaired Student's $t$ test; $N=2-$ 3 mice and $n=7-9$ total recordings/group) and vDG (right, $t_{(18)}=3.773,{ }^{* *} p=0.0014$; unpaired Student's $t$ test; $N=2-3$ mice and $n=10$ total recordings/group) excitatory neurons from Girk $7^{f / f l}$ mice treated with intra-vCA3/DG AAV8-CaMKII $\alpha$ Cre(mCherry) or AAV8-CaMKII $\alpha$-mCherry vector. $\boldsymbol{F}$, Summary of resting membrane potential (RMP) in vCA3 (left, $t_{(16)}=$ 1.155, $p=0.2652$; unpaired Student's $t$ test; $N=2-3$ mice and $n=8-10$ total recordings/group) and vDG (right, $t_{(18)}=$ $0.6257, p=0.5394$; unpaired Student's $t$ test; $N=2-3$ mice and $n=10$ total recordings/group) excitatory neurons from Girk $7^{f / f l}$ mice treated with intra-vHPC AAV8-CaMKII $\alpha$-Cre(mCherry) or AAV8-CaMKII $\alpha$-mCherry vector. $\boldsymbol{G}, \boldsymbol{H}$, Percentage of time spent in open and closed arms of the EPM by male Girk $7^{f / f f l}$ mice treated with intra-vCA3/DG Cre or control (con) vector, and either systemic vehicle (veh) or ML297 (30 mg/kg, i.p.). Group sizes ranged from 8-10 mice/group; ${ }^{* *} p<0.01$. I, Total distance traveled during the EPM test by male Girk $7^{\mathrm{fl} / f l}$ mice treated with intra-vCA3/DG (re or control (con) vector, and either systemic vehicle (veh) or ML297 (30 mg/kg, i.p.).

Given the evidence linking vCA1 pyramidal neurons to the expression of innate avoidance behavior, as well as our data showing that ML297 blunted the increase in EPM-induced c-Fos expression in vCA1, we were surprised to find that chemogenetic inhibition of vCA1 pyramidal neurons, achieved using three complementary approaches, had no impact on EPM performance. The distinct temporal profiles of vCA1 pyramidal neuron inhibition in optogenetic and chemogenetic studies may explain the different behavioral impact of these manipulations. vCA1 pyramidal neuron activity increased once mice entered the EPM open arms, rather than at decision points (Jimenez et al., 2018), and optogenetic inhibition of vCA1 pyramidal neurons on entry to EPM open arms suppressed expression of avoidance behavior. In our chemogenetic studies, vCA1 pyramidal neurons were likely inhibited before and throughout the duration of EPM testing.

While vCA1 pyramidal neuron inhibition did not impact EPM performance in male C57BL/6J mice, chemogenetic inhibition of excitatory neurons in $\mathrm{vCA} 3 / \mathrm{DG}$ increased EPM open arm time, as well as center time in open-field and light chamber time in the light-dark test. Our findings align well with a recent study demonstrating that chemogenetic inhibition of vHPC neurons in male rats reduced avoidance behaviors in EPM and light-dark tests (Maestas-Olguin et al., 2021), but this study did not provide anatomic separation between CA1 and CA3/ DG vHPC subregions. Besides approachavoidance conflict models, we also examined the effect of hM4Di-mediated inhibition of vCA3/DG neurons in the marble-burying test, an active-avoidance task in which mice work to minimize threatening stimuli. Excitotoxic lesioning of vHPC produced anxiolytic effects in EPM and marble-burying tests in male mice (Wang et al., 2019). Here, however, we observed no impact of vCA3/DG inhibition in active avoidance behavior. These different behavioral outcomes could be attributable to the different scope of persistent excitotoxic lesions and acute chemogenetic inhibition, including the lack of cell-type and subregion specificity in the former approach.

Furthermore, our Cre ablation efforts demonstrated that activation of GIRK1containing GIRK channels in vCA3/DG excitatory neurons is required for the suppression of avoidance behavior evoked by systemic ML297. Consistent with this premise, EPM exposure increased c-Fos expression in $\mathrm{vCA} 3$ and $\mathrm{vDG}$, as well as vCA1, and systemic ML297 administration suppressed the EPM-induced increase in cFos expression. Interestingly, our findings align well with a previous study showing that systemic diazepam-induced suppression of innate avoidance behavior in the EPM was lost in mice lacking $\alpha_{2}$-containing $\mathrm{GABA}_{\mathrm{A}}$ receptors in excitatory neurons in the DG and CA3, but not CA1 pyramidal neurons (Engin et al., 2016). Conversely, the effect of diazepam on conditioned fear required $\alpha_{2}$-containing $\mathrm{GABA}_{\mathrm{A}}$ receptors in vCA1 pyramidal neurons, but not in $\mathrm{CA} 3$ and DG excitatory neurons.

Collective chemogenetic inhibition of excitatory neurons in CA1, CA3, and DG subregions of the vHPC in C57BL/6 mice decreased avoidance behavior (Parfitt et al., 2017). Using the same viral vector and optimized targeting approaches, we demonstrate that this effect can be recapitulated by acute 
chemogenetic inhibition of excitatory neurons in vCA3/DG. Sequential excitatory synapses between DG granule cells, CA3 pyramidal neurons, and CA1 pyramidal neurons form a prominent unidirectional circuit within the HPC. The lack of impact of chemogenetic inhibition of vCA1 pyramidal neurons on EPM performance suggests that the inhibition of distinct circuits and projections involving vCA3 and vDG excitatory neurons underlies the suppression of avoidance behavior seen in our studies. Notably, selective chemogenetic inhibition of vHPC neurons projecting to the lateral septum (LS), most of which originate in $\mathrm{CA} 3$, increased innate avoidance behavior in the EPM test (Parfitt et al., 2017). Chemogenetic activation of the vHPC-LS projection decreased avoidance behavior, as did chemogenetic activation of excitatory neurons in the vDG that provide glutamatergic input to CA3 (Kheirbek et al., 2013). Thus, the suppression of avoidance behavior that we observed with chemogenetic inhibition of excitatory neurons in vCA3/DG likely occurred despite an opposing behavioral influence conferred by inhibition of the vHPC-LS projection.

In summary, we report here that GIRK channel activation in discrete limbic structures evokes divergent influence on innate avoidance behavior in male mice, and that ML297-induced inhibition of neurons in the vCA3/DG subregion of the vHPC is required for the suppression of avoidance behavior evoked by systemic ML297. We also present evidence that inhibition of excitatory neurons in the vCA3/DG subregion of the vHPC is sufficient to suppress innate avoidance behavior in male mice. Given the cross-species validity of approach avoidance conflict model as a translational measure of anxiety and avoidance behavior (Biedermann et al., 2017), our work suggests that future efforts targeting pharmacologic or genetic manipulations of GIRK channel activity in specific neuron populations might prove useful for treatment of anxiety-related disorders.

\section{References}

Adhikari A, Topiwala MA, Gordon JA (2010) Synchronized activity between the ventral hippocampus and the medial prefrontal cortex during anxiety. Neuron 65:257-269.

Adhikari A, Topiwala MA, Gordon JA (2011) Single units in the medial prefrontal cortex with anxiety-related firing patterns are preferentially influenced by ventral hippocampal activity. Neuron 71:898-910.

Adhikari A, Lerner TN, Finkelstein J, Pak S, Jennings JH, Davidson TJ, Ferenczi E, Gunaydin LA, Mirzabekov JJ, Ye L, Kim SY, Lei A, Deisseroth K (2015) Basomedial amygdala mediates top-down control of anxiety and fear. Nature 527:179-185.

An XL, Zou JX, Wu RY, Yang Y, Tai FD, Zeng SY, Jia R, Zhang X, Liu EQ, Broders $H$ (2011) Strain and sex differences in anxiety-like and social behaviors in C57BL/6J and BALB/cJ mice. Exp Anim 60:111-123.

Anacker C, Luna VM, Stevens GS, Millette A, Shores R, Jimenez JC, Chen B, Hen R (2018) Hippocampal neurogenesis confers stress resilience by inhibiting the ventral dentate gyrus. Nature 559:98-102.

Arnaudova I, Kindt M, Fanselow M, Beckers T (2017) Pathways towards the proliferation of avoidance in anxiety and implications for treatment. Behav Res Ther 96:3-13.

Bannerman DM, Grubb M, Deacon RM, Yee BK, Feldon J, Rawlins JN (2003) Ventral hippocampal lesions affect anxiety but not spatial learning. Behav Brain Res 139:197-213.

Bannerman DM, Sprengel R, Sanderson DJ, McHugh SB, Rawlins JN, Monyer H, Seeburg PH (2014) Hippocampal synaptic plasticity, spatial memory and anxiety. Nat Rev Neurosci 15:181-192.

Basu J, Siegelbaum SA (2015) The corticohippocampal circuit. Cold Spring Harb Perspect Biol 7:a021733.

Bettahi I, Marker CL, Roman MI, Wickman K (2002) Contribution of the Kir3.1 subunit to the muscarinic-gated atrial potassium channel $\mathrm{I}_{\mathrm{KACh}}$. $\mathrm{J}$ Biol Chem 277:48282-48288.

Biedermann SV, Biedermann DG, Wenzlaff F, Kurjak T, Nouri S, Auer MK, Wiedemann K, Briken P, Haaker J, Lonsdorf TB, Fuss J (2017) An elevated plus-maze in mixed reality for studying human anxiety-related behavior. BMC Biol 15:125.

Blednov YA, Stoffel M, Chang SR, Harris RA (2001) GIRK2 deficient mice. Evidence for hyperactivity and reduced anxiety. Physiol Behav 74:109-117.

Bourin M (2015) Animal models for screening anxiolytic-like drugs: a perspective. Dialogues Clin Neurosci 17:295-303.

Bystritsky A, Khalsa SS, Cameron ME, Schiffman J (2013) Current diagnosis and treatment of anxiety disorders. P T 38:30-57.

Calhoon GG, Tye KM (2015) Resolving the neural circuits of anxiety. Nat Neurosci 18:1394-1404.

Ciocchi S, Passecker J, Malagon-Vina H, Mikus N, Klausberger T (2015) Brain computation. Selective information routing by ventral hippocampal CA1 projection neurons. Science 348:560-563.

Dimidschstein J, Chen Q, Tremblay R, Rogers SL, Saldi GA, Guo L, Xu Q, Liu R, Lu C, Chu J, Grimley JS, Krostag AR, Kaykas A, Avery MC, Rashid MS, Baek M, Jacob AL, Smith GB, Wilson DE, Kosche G, et al. (2016) A viral strategy for targeting and manipulating interneurons across vertebrate species. Nat Neurosci 19:1743-1749.

D'Souza D, Sadananda M (2017) Estrous cycle phase-dependent changes in anxiety- and depression-like profiles in the late adolescent Wistar-Kyoto rat. Ann Neurosci 24:136-145.

Engin E, Smith KS, Gao Y, Nagy D, Foster RA, Tsvetkov E, Keist R, Crestani F, Fritschy JM, Bolshakov VY, Hajos M, Heldt SA, Rudolph U (2016) Modulation of anxiety and fear via distinct intrahippocampal circuits. Elife 5:e14120.

Fanselow MS, Dong HW (2010) Are the dorsal and ventral hippocampus functionally distinct structures? Neuron 65:7-19.

Felix-Ortiz AC, Beyeler A, Seo C, Leppla CA, Wildes CP, Tye KM (2013) BLA to vHPC inputs modulate anxiety-related behaviors. Neuron 79:658-664.

Felix-Ortiz AC, Burgos-Robles A, Bhagat ND, Leppla CA, Tye KM (2016) Bidirectional modulation of anxiety-related and social behaviors by amygdala projections to the medial prefrontal cortex. Neuroscience 321:197-209.

Gallo FT, Katche C, Morici JF, Medina JH, Weisstaub NV (2018) Immediate early genes, memory and psychiatric disorders: focus on c-Fos, Egr1 and Arc. Front Behav Neurosci 12:79.

Hearing M, Kotecki L, Marron Fernandez de Velasco E, Fajardo-Serrano A, Chung HJ, Luján R, Wickman K (2013) Repeated cocaine weakens GABA (B)-Girk signaling in layer $5 / 6$ pyramidal neurons in the prelimbic cortex. Neuron 80:159-170.

Hendriks SM, Spijker J, Licht CM, Hardeveld F, de Graaf R, Batelaan NM, Penninx BW, Beekman AT (2016) Long-term disability in anxiety disorders. BMC Psychiatry 16:248.

Hofmann SG, Hay AC (2018) Rethinking avoidance: toward a balanced approach to avoidance in treating anxiety disorders. J Anxiety Disord 55:14-21.

Janak PH, Tye KM (2015) From circuits to behaviour in the amygdala. Nature 517:284-292.

Jimenez JC, Su K, Goldberg AR, Luna VM, Biane JS, Ordek G, Zhou P, Ong SK, Wright MA, Zweifel L, Paninski L, Hen R, Kheirbek MA (2018) Anxiety cells in a hippocampal-hypothalamic circuit. Neuron 97:670-683.e6.

Karschin C, Dissmann E, Stuhmer W, Karschin A (1996) IRK(1-3) and GIRK(1-4) inwardly rectifying $\mathrm{K}^{+}$channel mRNAs are differentially expressed in the adult rat brain. J Neurosci 16:3559-3570.

Kaufmann K, Romaine I, Days E, Pascual C, Malik A, Yang L, Zou B, Du Y, Sliwoski G, Morrison RD, Denton J, Niswender CM, Daniels JS, Sulikowski GA, Xie XS, Lindsley CW, Weaver CD (2013) ML297 (VU0456810), the first potent and selective activator of the GIRK potassium channel, displays antiepileptic properties in mice. ACS Chem Neurosci 4:1278-1286.

Kheirbek MA, Drew LJ, Burghardt NS, Costantini DO, Tannenholz L, Ahmari SE, Zeng H, Fenton AA, Hen R (2013) Differential control of learning and anxiety along the dorsoventral axis of the dentate gyrus. Neuron 77:955-968.

Kjelstrup KG, Tuvnes FA, Steffenach HA, Murison R, Moser EI, Moser MB (2002) Reduced fear expression after lesions of the ventral hippocampus. Proc Natl Acad Sci USA 99:10825-10830.

Kohara K, Pignatelli M, Rivest AJ, Jung HY, Kitamura T, Suh J, Frank D, Kajikawa K, Mise N, Obata Y, Wickersham IR, Tonegawa S (2014) Cell type-specific genetic and optogenetic tools reveal hippocampal CA2 circuits. Nat Neurosci 17:269-279. 
Kotecki L, Hearing M, McCall NM, Marron Fernandez de Velasco E, Pravetoni M, Arora D, Victoria NC, Munoz MB, Xia Z, Slesinger PA, Weaver CD, Wickman K (2015) GIRK channels modulate opioidinduced motor activity in a cell type- and subunit-dependent manner. J Neurosci 35:7131-7142.

Koyrakh L, Luján R, Colon J, Karschin C, Kurachi Y, Karschin A, Wickman K (2005) Molecular and cellular diversity of neuronal G-protein-gated potassium channels. J Neurosci 25:11468-11478.

Krashes MJ, Koda S, Ye C, Rogan SC, Adams AC, Cusher DS, Maratos-Flier E, Roth BL, Lowell BB (2011) Rapid, reversible activation of AgRP neurons drives feeding behavior in mice. J Clin Invest 121:1424-1428.

Law AMK, Yin JXM, Castillo L, Young AIJ, Piggin C, Rogers S, Caldon CE, Burgess A, Millar EKA, O'Toole SA, Gallego-Ortega D, Ormandy CJ, Oakes SR (2017) Andy's algorithms: new automated digital image analysis pipelines for FIJI. Sci Rep 7:15717.

Lecca S, Pelosi A, Tchenio A, Moutkine I, Luján R, Hervé D, Mameli M (2016) Rescue of GABA and GIRK function in the lateral habenula by protein phosphatase $2 \mathrm{~A}$ inhibition ameliorates depression-like phenotypes in mice. Nat Med 22:254-261.

Lein ES, Hawrylycz MJ, Ao N, Ayres M, Bensinger A, Bernard A, Boe AF, Boguski MS, Brockway KS, Byrnes EJ, Chen L, Chen L, Chen TM, Chin MC, Chong J, Crook BE, Czaplinska A, Dang CN, Datta S, Dee NR, et al. (2007) Genome-wide atlas of gene expression in the adult mouse brain. Nature 445:168-176.

Linden AM, Greene SJ, Bergeron M, Schoepp DD (2004) Anxiolytic activity of the MGLU2/3 receptor agonist LY354740 on the elevated plus maze is associated with the suppression of stress-induced c-Fos in the hippocampus and increases in c-Fos induction in several other stress-sensitive brain regions. Neuropsychopharmacology 29:502-513.

Luján R, Aguado C (2015) Localization and targeting of GIRK channels in mammalian central neurons. Int Rev Neurobiol 123:161-200.

Luján R, Marron Fernandez de Velasco E, Aguado C, Wickman K (2014) New insights into the therapeutic potential of GIRK channels. Trends Neurosci 37:20-29.

Lüscher C, Slesinger PA (2010) Emerging roles for G protein-gated inwardly rectifying potassium (GIRK) channels in health and disease. Nat Rev Neurosci 11:301-315.

Lüscher C, Jan LY, Stoffel M, Malenka RC, Nicoll RA (1997) G protein-coupled inwardly rectifying $\mathrm{K}^{+}$channels (GIRKs) mediate postsynaptic but not presynaptic transmitter actions in hippocampal neurons. Neuron 19:687-695.

Maestas-Olguin C, Fennelly JW, Pentkowski NS (2021) Chemogenetic inhibition of ventral hippocampal CaMKII $\alpha$-expressing neurons attenuates anxiety- but not fear-like defensive behaviors in male Long-Evans hooded rats. Neurosci Lett 751:135777.

Manassero E, Renna A, Milano L, Sacchetti B (2018) Lateral and basal amygdala account for opposite behavioral responses during the long-term expression of fearful memories. Sci Rep 8:518.

Marcondes FK, Miguel KJ, Melo LL, Spadari-Bratfisch RC (2001) Estrous cycle influences the response of female rats in the elevated plus-maze test. Physiol Behav 74:435-440.

Marron Fernandez de Velasco E, Carlblom N, Xia Z, Wickman K (2017) Suppression of inhibitory $G$ protein signaling in forebrain pyramidal neurons triggers plasticity of glutamatergic neurotransmission in the nucleus accumbens core. Neuropharmacology 117:33-40.

Nakazawa K, Quirk MC, Chitwood RA, Watanabe M, Yeckel MF, Sun LD, Kato A, Carr CA, Johnston D, Wilson MA, Tonegawa S (2002) Requirement for hippocampal CA3 NMDA receptors in associative memory recall. Science 297:211-218.

Okuyama T, Kitamura T, Roy DS, Itohara S, Tonegawa S (2016) Ventral CA1 neurons store social memory. Science 353:1536-1541.

Oler JA, Fox AS, Shelton SE, Rogers J, Dyer TD, Davidson RJ, Shelledy W, Oakes TR, Blangero J, Kalin NH (2010) Amygdalar and hippocampal substrates of anxious temperament differ in their heritability. Nature 466:864-868.

Padilla-Coreano N, Bolkan SS, Pierce GM, Blackman DR, Hardin WD, Garcia-Garcia AL, Spellman TJ, Gordon JA (2016) Direct ventral hippocampal-prefrontal input is required for anxiety-related neural activity and behavior. Neuron 89:857-866.

Padilla-Coreano N, Canetta S, Mikofsky RM, Alway E, Passecker J, Myroshnychenko MV, Garcia-Garcia AL, Warren R, Teboul E, Blackman DR, Morton MP, Hupalo S, Tye KM, Kellendonk C,
Kupferschmidt DA, Gordon JA (2019) Hippocampal-prefrontal theta transmission regulates avoidance behavior. Neuron 104:601-610.e4.

Parfitt GM, Nguyen R, Bang JY, Aqrabawi AJ, Tran MM, Seo DK, Richards BA, Kim JC (2017) Bidirectional control of anxiety-related behaviors in mice: role of inputs arising from the ventral hippocampus to the lateral septum and medial prefrontal cortex. Neuropsychopharmacology 42:1715-1728.

Pravetoni M, Wickman K (2008) Behavioral characterization of mice lacking GIRK/Kir3 channel subunits. Genes Brain Behav 7:523-531.

Schumacher A, Villaruel FR, Ussling A, Riaz S, Lee ACH, Ito R (2018) Ventral hippocampal CA1 and CA3 differentially mediate learned approach-avoidance conflict processing. Curr Biol 28:1318-1324.e4.

Silveira MC, Sandner G, Graeff FG (1993) Induction of Fos immunoreactivity in the brain by exposure to the elevated plus-maze. Behav Brain Res 56:115-118.

Slesinger PA, Wickman K, eds (2015) Structure to function of G proteingated inwardly rectifying (GIRK) channels. San Diego: Elsevier.

Sorregotti T, Cipriano AC, Cruz FC, Mascarenhas DC, Rodgers RJ, Nunes-deSouza RL (2018) Amygdaloid involvement in the defensive behavior of mice exposed to the open elevated plus-maze. Behav Brain Res 338:159-165.

Strawn JR, Geracioti L, Rajdev N, Clemenza K, Levine A (2018) Pharmacotherapy for generalized anxiety disorder in adult and pediatric patients: an evidence-based treatment review. Expert Opin Pharmacother 19:1057-1070.

Stujenske JM, Likhtik E, Topiwala MA, Gordon JA (2014) Fear and safety engage competing patterns of theta-gamma coupling in the basolateral amygdala. Neuron 83:919-933.

Tamamaki N, Yanagawa Y, Tomioka R, Miyazaki J, Obata K, Kaneko T (2003) Green fluorescent protein expression and colocalization with calretinin, parvalbumin, and somatostatin in the GAD67-GFP knock-in mouse. J Comp Neurol 467:60-79.

Tipps M, Marron Fernandez de Velasco E, Schaeffer A, Wickman K (2018) Inhibition of pyramidal neurons in the basal amygdala promotes fear learning. eNeuro 5:ENEURO.0272-18.2018.

Tye KM, Prakash R, Kim SY, Fenno LE, Grosenick L, Zarabi H, Thompson KR, Gradinaru V, Ramakrishnan C, Deisseroth K (2011) Amygdala circuitry mediating reversible and bidirectional control of anxiety. Nature 471:358-362.

Victoria NC, Marron Fernandez de Velasco E, Ostrovskaya O, Metzger S, Xia Z, Kotecki L, Benneyworth MA, Zink AN, Martemyanov KA, Wickman K (2016) $\mathrm{G}$ protein-gated $\mathrm{K}^{+}$channel ablation in forebrain pyramidal neurons selectively impairs fear learning. Biol Psychiatry 80:796-806.

Vo BN, Abney KK, Anderson A, Marron Fernandez de Velasco E, Benneyworth MA, Daniels JS, Morrison RD, Hopkins CR, Weaver CD, Wickman K (2019) VU0810464, a non-urea G protein-gated inwardly rectifying $\mathrm{K}^{+}\left(\mathrm{K}_{\mathrm{ir}} 3 / \mathrm{GIRK}\right)$ channel activator, exhibits enhanced selectivity for neuronal $\mathrm{K}_{\mathrm{ir}} 3$ channels and reduces stress-induced hyperthermia in mice. Br J Pharmacol 176:2238-2249.

Wang C, Zhang Y, Shao S, Cui S, Wan Y, Yi M (2019) Ventral hippocampus modulates anxiety-like behavior in male but not female C57BL/6 J mice. Neuroscience 418:50-58.

Wang DV, Wang F, Liu J, Zhang L, Wang Z, Lin L (2011) Neurons in the amygdala with response-selectivity for anxiety in two ethologically based tests. PLoS One 6:e18739.

Weeden CS, Roberts JM, Kamm AM, Kesner RP (2015) The role of the ventral dentate gyrus in anxiety-based behaviors. Neurobiol Learn Mem 118:143-149.

Wydeven N, Marron Fernandez de Velasco E, Du Y, Benneyworth MA, Hearing MC, Fischer RA, Thomas MJ, Weaver CD, Wickman K (2014) Mechanisms underlying the activation of G-protein-gated inwardly rectifying $\mathrm{K}^{+}$(GIRK) channels by the novel anxiolytic drug, ML297. Proc Natl Acad Sci USA 111:10755-10760.

Yang Y, Wang JZ (2017) From structure to behavior in basolateral amygdalahippocampus circuits. Front Neural Circuits 11:86.

Yizhar O, Fenno LE, Davidson TJ, Mogri M, Deisseroth K (2011) Optogenetics in neural systems. Neuron 71:9-34.

Yohn CN, Shifman S, Garino A, Diethorn E, Bokka L, Ashamalla SA, Samuels BA (2020) Fluoxetine effects on behavior and adult hippocampal neurogenesis in female C57BL/6J mice across the estrous cycle. Psychopharmacology (Berl) 237:1281-1290. 